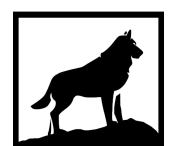

Michigan

Technological

1 8 8 5 University
Michigan Technological University

Digital Commons @ Michigan Tech

Dissertations, Master's Theses and Master's Reports

2020

INCREASING ACCESS TO PV TECHNOLOGY THROUGH

SUSTAINABLE RACKING: A REVIEW OF EXISTING LITERATURE

AND GROUND MOUNTED FIXED TILT DESIGNS, AND WHAT CAN

BE DONE NEXT

Parijata Prabhakara

Michigan Technological University, pprabhak@mtu.edu

Copyright 2020 Parijata Prabhakara

Recommended Citation

Prabhakara, Parijata, "INCREASING ACCESS TO PV TECHNOLOGY THROUGH SUSTAINABLE RACKING: A REVIEW OF EXISTING LITERATURE AND GROUND MOUNTED FIXED TILT DESIGNS, AND WHAT CAN BE DONE NEXT", Open Access Master's Report, Michigan Technological University, 2020.

https://doi.org/10.37099/mtu.dc.etdr/1017

Follow this and additional works at: https://digitalcommons.mtu.edu/etdr

Part of the Applied Mechanics Commons, Engineering Mechanics Commons, Mechanics of Materials Commons, and the Structural Materials Commons 


\title{
INCREASING ACCESS TO PV TECHNOLOGY THROUGH SUSTAINABLE RACKING: A REVIEW OF EXISTING LITERATURE AND GROUND MOUNTED FIXED TILT DESIGNS, AND WHAT CAN BE DONE NEXT
}

By

Parijata Prabhakara

\author{
A REPORT \\ Submitted in partial fulfillment of the requirements for the degree of \\ MASTER OF SCIENCE \\ In Mechanical Engineering \\ MICHIGAN TECHNOLOGICAL UNIVERSITY \\ 2020 \\ (C) 2020 Parijata Prabhakara
}


This report has been approved in partial fulfillment of the requirements for the Degree of MASTER OF SCIENCE in Mechanical Engineering.

Department of Mechanical Engineering - Engineering Mechanics

\author{
Report Advisor: Dr. Craig Friedrich \\ Committee Member: Dr. Kari Henquinet \\ Committee Member: Dr. Joshua Pearce
}

Department Chair: Dr. William W. Predebon 


\section{TABLE OF CONTENTS}

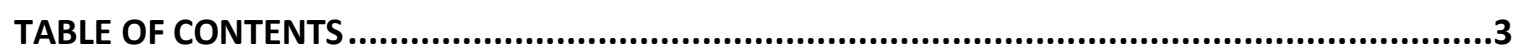

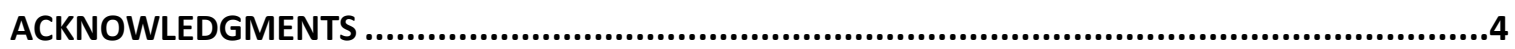

ABSTRACT

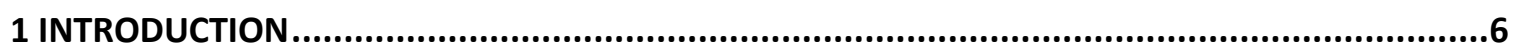

2 BACKGROUND: SUSTAINABLE DEVELOPMENT WORK AND PEACE CORPS PERUCHAPTER $3 \ldots . .8$

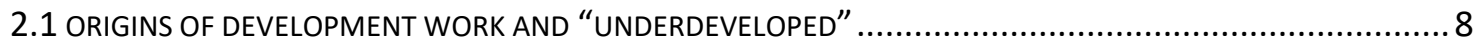

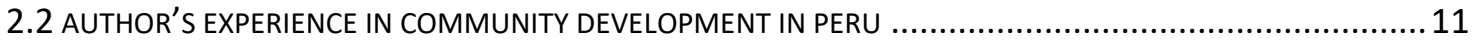

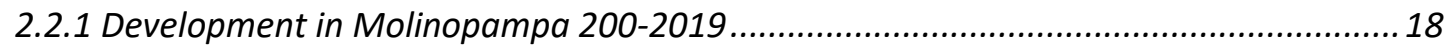

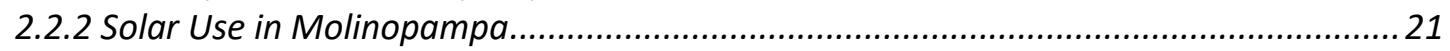

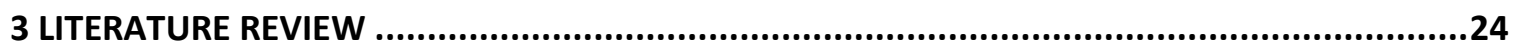

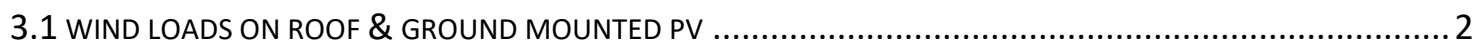

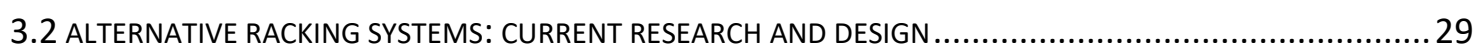

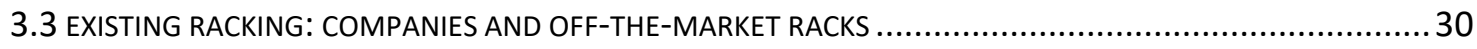

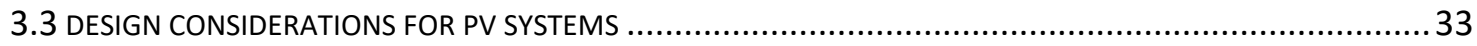

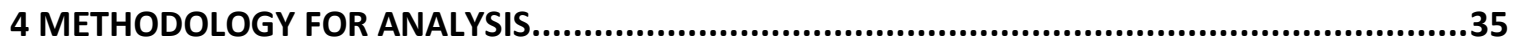

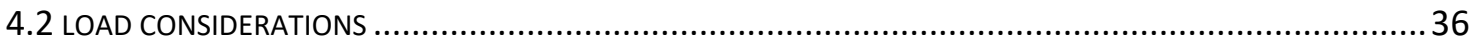

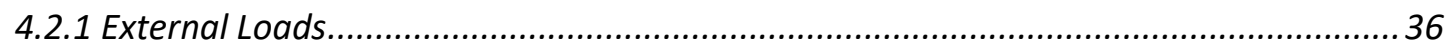

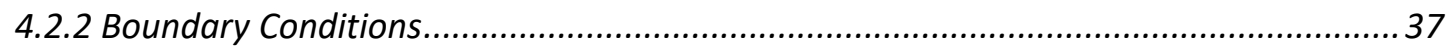

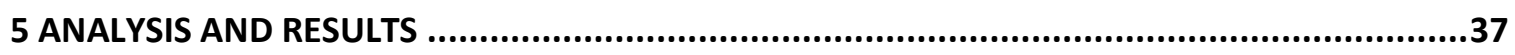

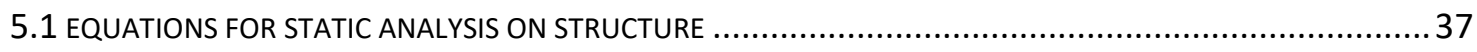

5.2 ANALYSIS ON SIMPLE DIY STRUCTURE

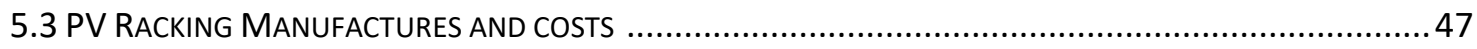

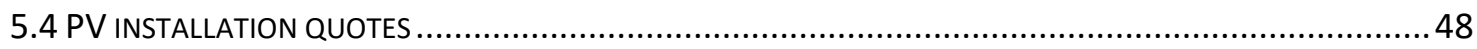

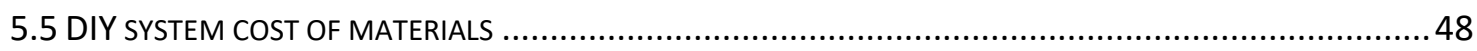

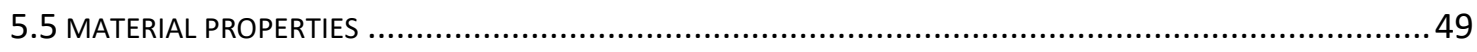

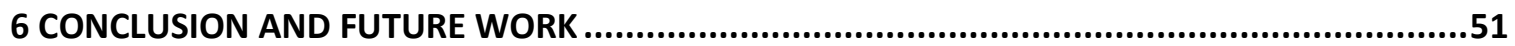

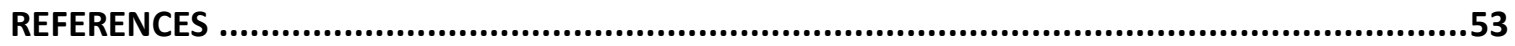




\section{Acknowledgements}

I would like to thank my advisor Dr. Craig Friedrich and committee members Dr. Kari Henquinet and Dr. Joshua Pearce for their guidance and continued support.

Thanks to the community of Molinopampa and department of Amazonas and Peruvian people for welcoming me into their community. Thanks to my family (Prabha, Kalpana, Guru), friends, and animal companions for their support always. 


\section{Abstract}

There is a lack of literature on the structural balance of systems (BOS), also called racking, for ground mount, fixed-tilt solar PV systems. Literature that exists discusses mostly rooftop racking and installations, additional wind loading, and weight considerations imposed on roofs, and little guidance is provided in building codes. The lack of peer-reviewed guidance on design requirements for domestic and large-scale application solar PV racking systems leaves most consumers relying on expensive, patented, off-the-shelf hardware. As PV cell technology and module costs have improved, we can start to focus on PV BOS improvements (particularly racking) and move towards sustainable designs that contribute to lower the overall cost of PV systems, increasing their accessibility especially for developing, low-income, or remote communities. The purpose of this paper is to review existing literature on fixed-tilt, ground-mount PV racking systems, present methods of analyzing DIY systems, and suggest

further research. The paper is presented in the context of community development work and the author's experience as a Peace Corps volunteer in Peru. 


\section{Introduction}

More than 1 billion people lack access to electricity and about $60 \%$ of the world's population lives in rural areas (Holmes et al 2015). More than $80 \%$ of those who lack access to electricity live in rural areas (IEA 2019). For many of those who do have access to electricity, the source is unreliable and inconsistent. Access to energy is critical to a community's economic growth and conventionally, a community's wellbeing. The cost and time of expanding electrical power distribution to rural areas is expensive and relies on government initiatives. $67 \%$ of the world's electricity is produced by means of combustion: $38 \%$ being coal, $23 \%$ natural gas, and 6\% oil, biofuel, or other fuel (EIA 2019). PV for energy production on small and large scales can serve as solutions to various global issues including climate change, decentralization of energy generation, sustainable development, empowerment through autonomy and in many cases economic benefits to the proprietor (Pearce 2002).

Although still evolving, the cost of solar panels has appreciably decreased over several years due to solar cell technology improvements. The price per module in the US has decreased over 60\% from about USD 8.50/watt 10 years ago, to an average of USD 3.05/watt in 2019 (Matasci, Sara, 2019). Economies of scale influences cost of solar and generally benefits large corporations, governments and those investing in commercial or utility scale PV projects. Smaller residential systems between $2-4 \mathrm{~kW}$ may cost $15 \%$ more than $8-10 \mathrm{~kW}$ residential systems. While the overall cost of solar has decreased, and continues to decrease, BOS still makes up for $30-50 \%$ of the entire PV installation cost (Feldman et al 2015, Matasci, Sara 2019). Now that price of modules has decreased due to improvements in cell technology, manufacturing, and efficiency, PV racking design and manufacturing can improve to reduce BOS 
costs. In 2017 the price of structural BOS was USD 0.11/W structural. Total electrical and structural BOS dropped from USD 0.4 to USD 0.31 for residential systems, USD 0.63 to USD 0.26 for commercial systems, and USD 0.66 to USD 0.22 for utility scale applications between the year 2010 and 2017 (Fu et al 2017). Incentives such as a federal tax credit in the US, allow consumers to claim $30 \%$ tax credit on purchasing price of their PV system; however, this is not a good enough incentive and does not make solar affordable to the masses.

In the United States for example, the average residential PV system is about 5kW, which may consist of 20 modules if the modules are rated at $250 \mathrm{~W}$. The upfront cost of a residential system of this size may cost between USD 13,000 to USD 25,000 depending on the price per watt. While installers advertise a ten to twenty-year payback period, the initial upfront cost of solar makes this technology inaccessible to the masses in the US or anywhere else in the world. Because of PV technology improvements, solar panels cost less than their racking systems. Working to reduce these costs through sustainable design can help increase access to PV technology making it a viable and sustainable source of energy especially in the context of development work. 


\section{Background: Sustainable Development Work and Peace}

\section{Corps in Peru}

Exploring sustainable technology can benefit all communities -rural, urban, domestic, international. Dissemination of affordable open-source technologies, especially those such as PV technology can increase individual and community autonomy by decreasing dependence on capitalist systems through creation of decentralized energy generation.

\subsection{Origins of Development Work and "Underdeveloped"}

The term development as it is used today (community development, developing country), gained popularity after World War II in 1949 when President Truman described in his inaugural speech the global south as "underdeveloped" and requiring help from "developed" countries such as the United States (global north). Originally the term had a violent and exploitative connotation when used during the era of imperialism, a means to civilize native people, a term used as an excuse to conquer and exploit lands rich in natural resources. The goal set forth by Truman was to move away from the violent colonial connotation and introduce new methods of development, such as an extension of being a good neighbor: "We must embark on a bold new program for making the benefits of our scientific advances and industrial progress avail-able for the improvement and growth of underdeveloped areas. The old imperialism - exploitation for foreign profit - has no place in our plans. What we envisage is a program of development based on the concepts of democratic fair dealing" (Harry S. Truman, 1949 Inaugural Speech). 
Defining more than half of the world as "underdeveloped" that required help form the US was a guise for the U.S. to establish their hegemony and maintain global power, "By using for the first time in such context the word 'underdeveloped', Truman changed the meaning of development and created the emblem, a euphemism, used ever since to allude either discreetly or inadvertently to the era of American hegemony" (Gustavo Esteva, Development Dictionary).

"Development" has been used to describe biological processes, and eventually was adopted to describe social change entiwcklung. Biologically for example, reaching full potential or completion of stages, growth of organisms to reach genetic potential, and if an organism does not develop normally and function or behavior is compromised -this would be a flaw in development (imperfect). Development is directional: Always advancing --inferior to superior, worst to better; however, based on Western terms and concepts of advancement, quality of life, morals, and most of the time driven by capitalism.

The Spirit of Regeneration: Andean Culture Confronting Western Notions of Development is a work of Peruvian ideologies and writings from an Andean campesino (peasant) perspective that challenge western epistemologies of development. On one hand, the desire to achieve development may be for economic growth including infrastructure improvements, access to technology, social equality, and/or needs to basic human rights such as access to clean water. However, economic development itself does not look the same to the US as it might for example to a native community in the Sierras or Jungle of Peru. To what extent is it appropriate for outsiders to promote sustainable programs, technologies, etc. to communities they are not inherently a part of? 
Although there are trends in development work movements to attempt to reject the old exploitative ways and reestablish itself as sustainable and grassroots led, it is still performed as an extension of colonialism (as the author witnessed in the context of Peace Corps). How are development strategies and programs defined, and by what standards? There are two options for development work: one as the Development Dictionary suggests is to reject international development work altogether or work pragmatically within a system that exists to help global challenges such as malnutrition and access to clean water. If development work is done, organizations and individuals must be mindful and careful of the work they do. While the motivation for exploring low cost solar racking in this paper was driven by the author's experience in sustainable development in Peru, it should be noted that international community development work is not the only platform for exploring sustainable technology such as PV racking systems. A great example of sustainable PV applications would be in the recent case of the 2018-2019 California wildfires, when Pacific Gas \& Electric Company (PG\&E) mandated forced power outages in various regions to prevent wildfires they caused with faulty, outdated transmission lines. Millions of Californians were left without power, and greatly affecting patients whose lives depend on health care systems. PV technology would eliminate the need for this type of distribution and unjust administration of electricity. With respect to community development work, it may be helpful to shift efforts domestically. 


\subsection{Author's Experience in Community Development in Peru}

The author lived and worked as a water and sanitation engineer in Molinopampa, Peru for three years between September 2014 and December 2017. Peru is a country in South America located just south of the equator, sharing a border with Ecuador, Colombia, Brazil, Bolivia, Chile, and the Pacific Ocean along its western coast. Peru is generally divided into three main geographical regions: coast, highlands -including the Andes, and jungle -including the Amazon rainforest. The varied geography contributes to Peru's rich biodiversity. Peru is also extremely diverse with respect to culture, language, and ethnicity.

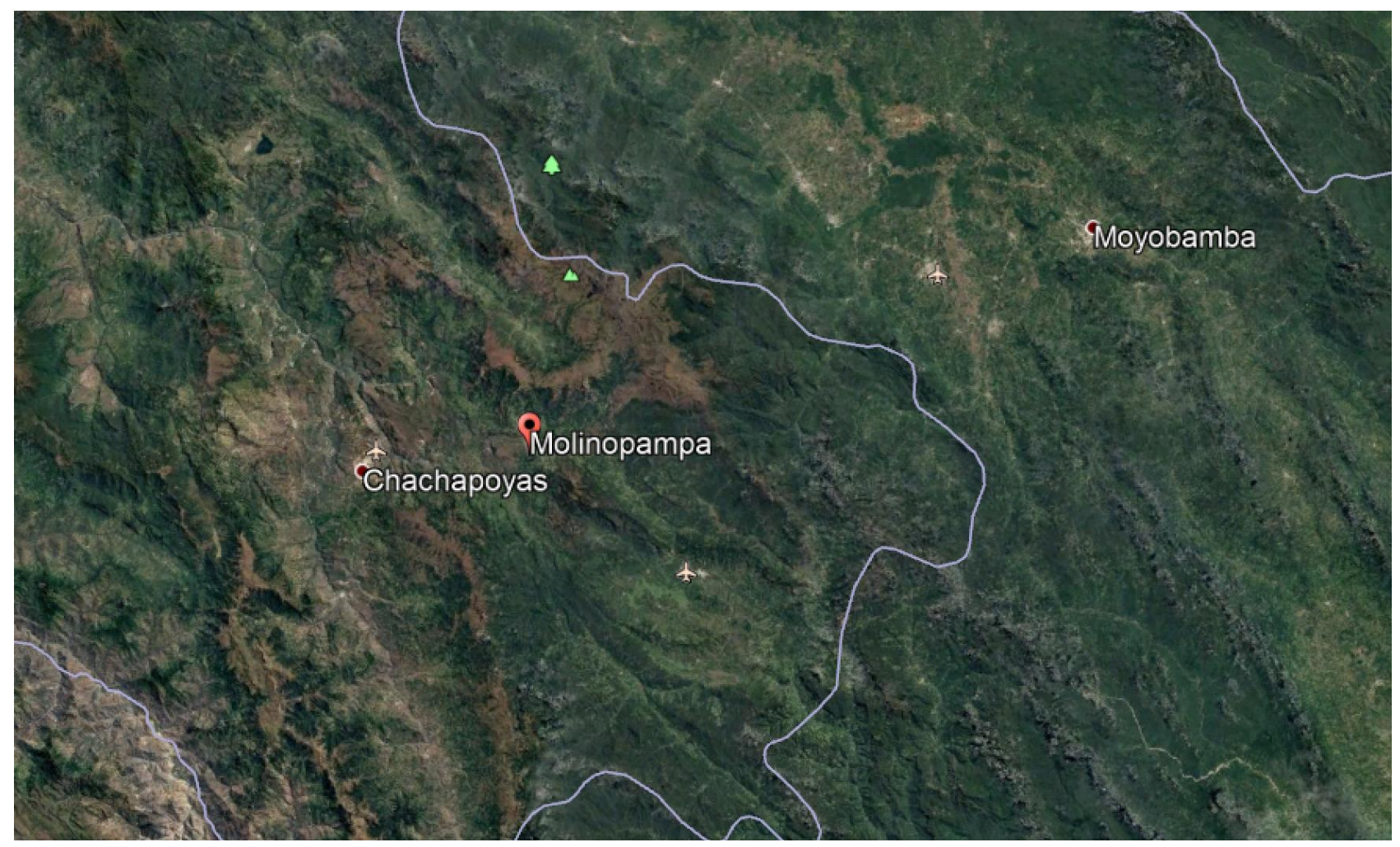

Figure 1 Location of Molinopampa with respect to the provincial capital of Amazonas (Chachapoyas) and San Martin 
Peru consists of 24 departments. Molinopampa is in the department of Amazonas, province of Chachapoyas, between the Andes mountain range and Jungle (Amazon Basin) at an elevation of $2400 \mathrm{~m}$ above sea level, contributing to its unique geography, climate, biodiversity, and culture. Molinopampa is the district capital and sits in a small valley at 2,400 meters above sea level, with rural towns expending east to the next town Rodriguez de Mendoza, progressively lowering in elevation. Because of the drop in elevation of over 1000 meters east from Molinopampa, Rodriguez de Mendoza are growers of coffee (Figure 7), pineapple, mango, guava, and avocado. This region is known as the "seja de selva" or the "eyebrow of the jungle," with unique climate, geography, culture, flora and fauna, high wetlands, orchids, "oso de anteojos" (bear with glasses) and the only palm forest of its kind at this elevation (Figure 9). Ruins of the pre-Incan Chachapoyas community can be found throughout Molinopampa and surrounding districts. Many people still speak Quechua, and native languages such as Aymara, Awajun, and Quechua have influenced the style of Spanish spoken today. The people of Molinopampa were mostly crop farmers until the dairy industry made its way east and dairy farming promised immediate and consistent profit. In the last 50 years, Molinopampa has transitioned from primarily an agriculture, crop farming and subsistence farming community to a dairy and cattle farming dominant community (Figure 2) -producing and selling dairy products locally and to neighboring departments. 


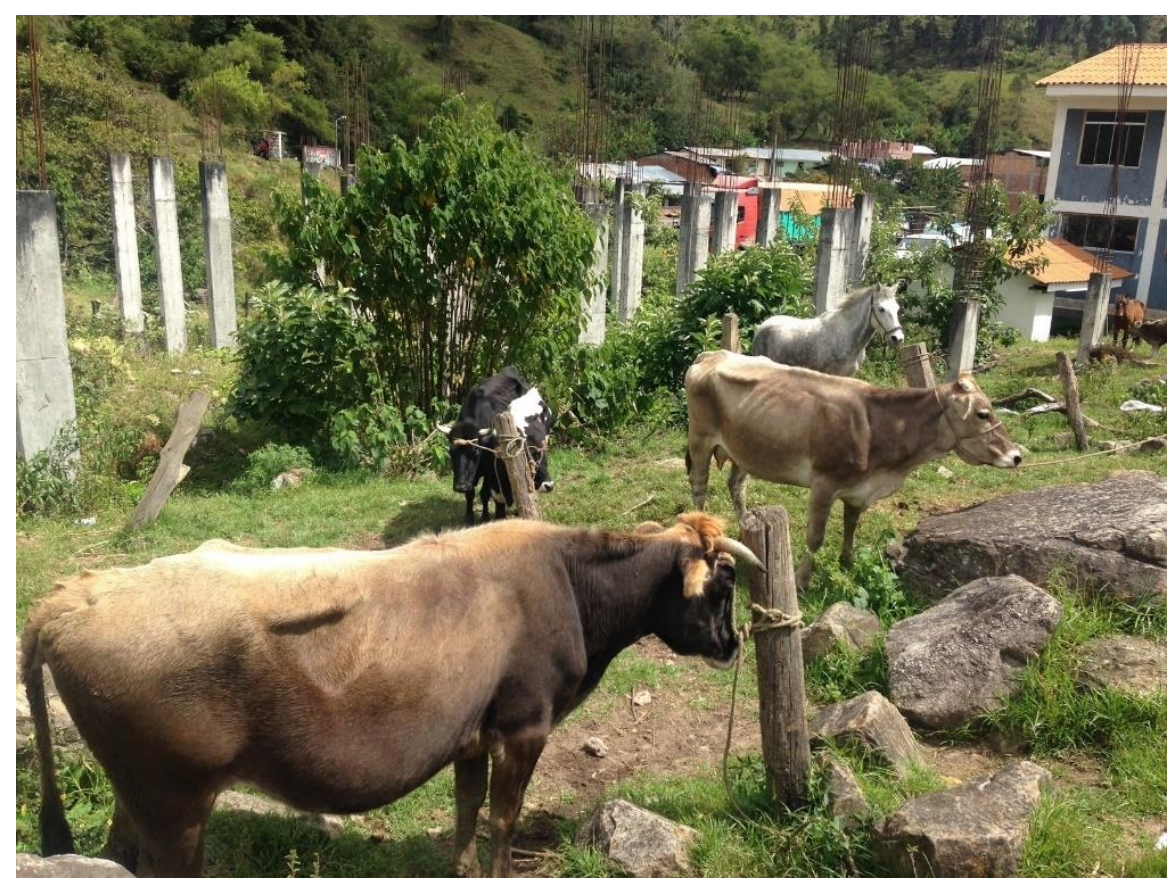

Figure 2 Weekly Sunday Cattle Market in Pipus, Chachapoyas, 10 km from Molinopampa

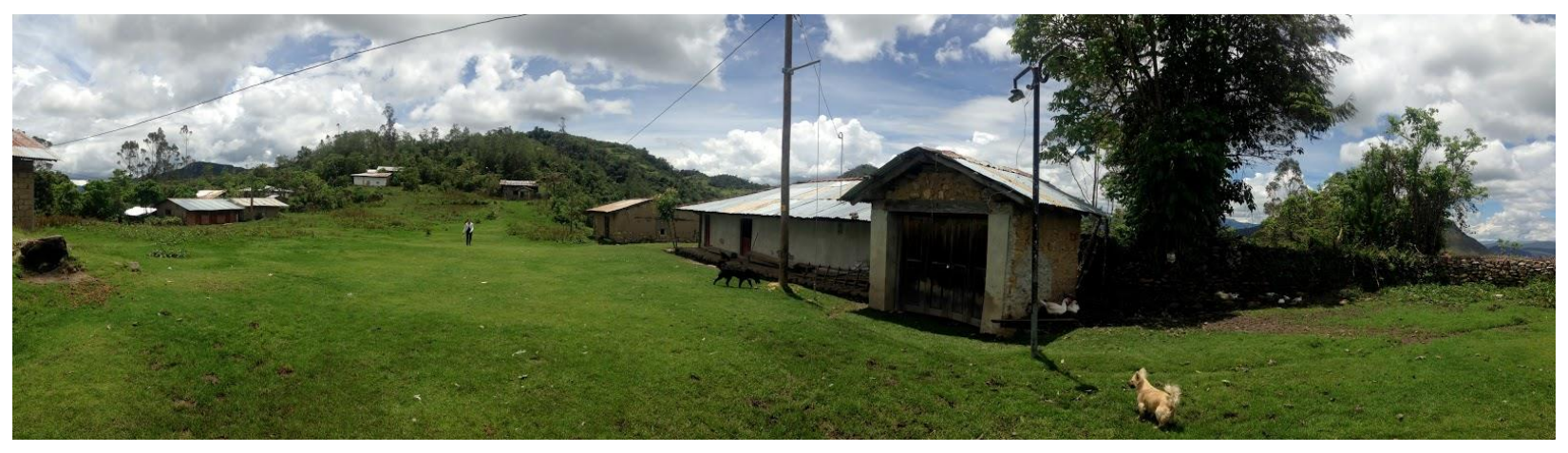

Figure 3 Original Town of Molinopampa, Known as Taulia 


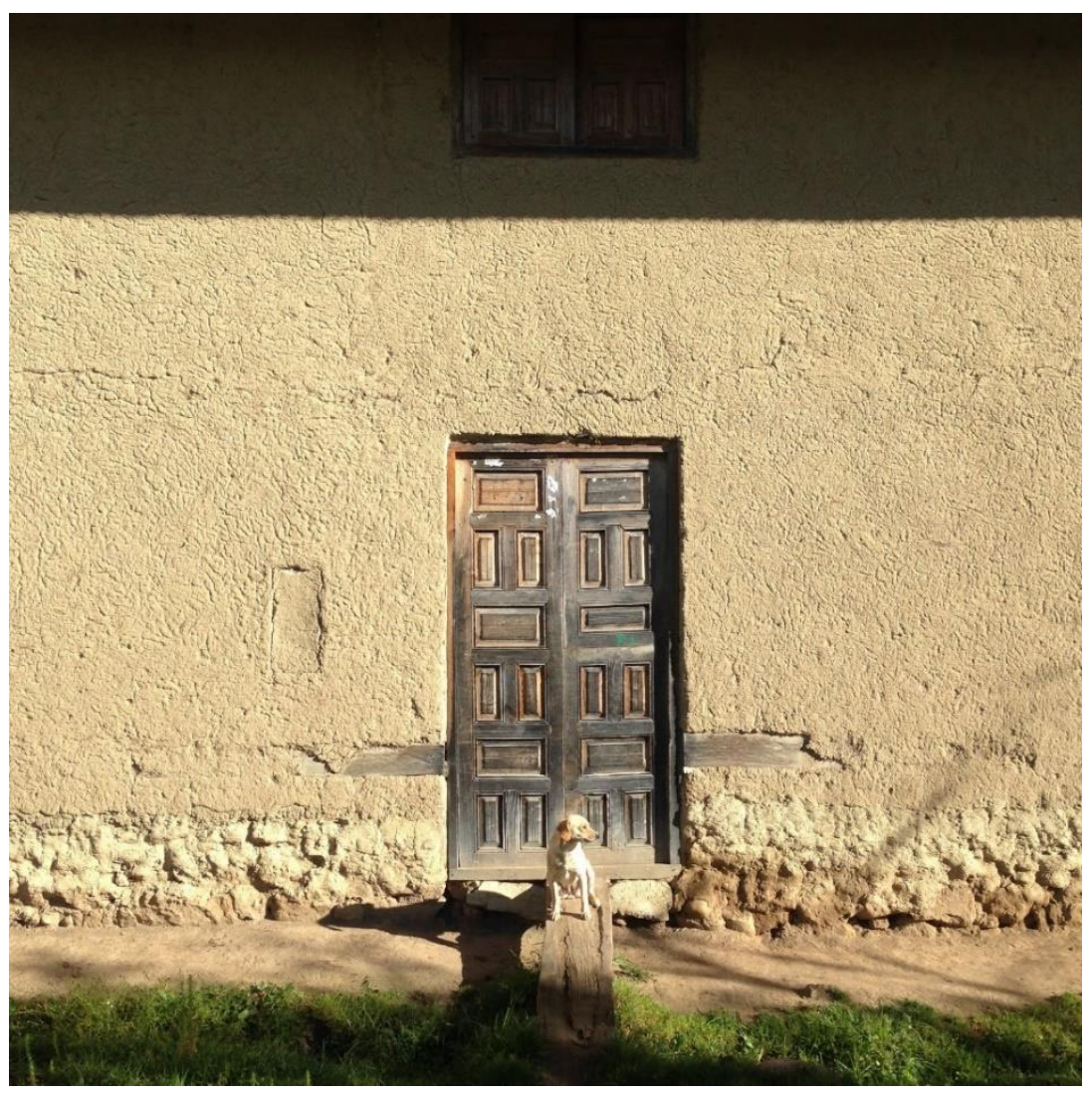

Figure 4 Traditional Adobe Style Home; Homes and Buildings are Constructed with Masonry in the last 10 years.

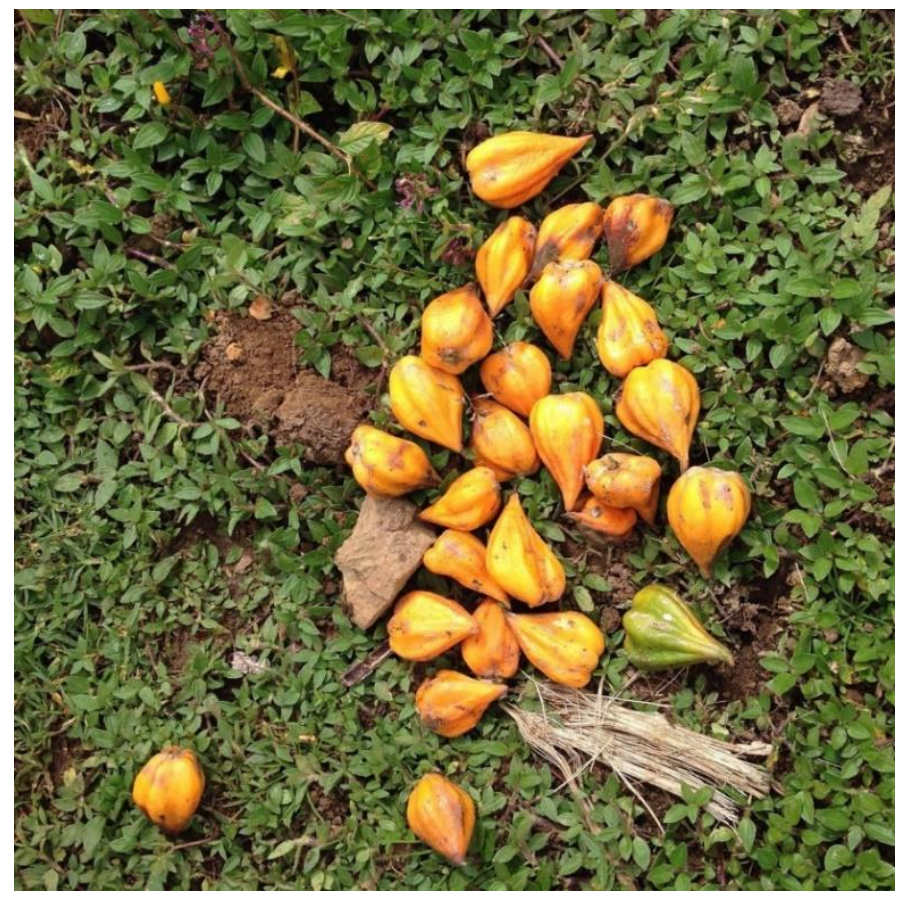

Figure 5 Native Fruit, "Maushon" 


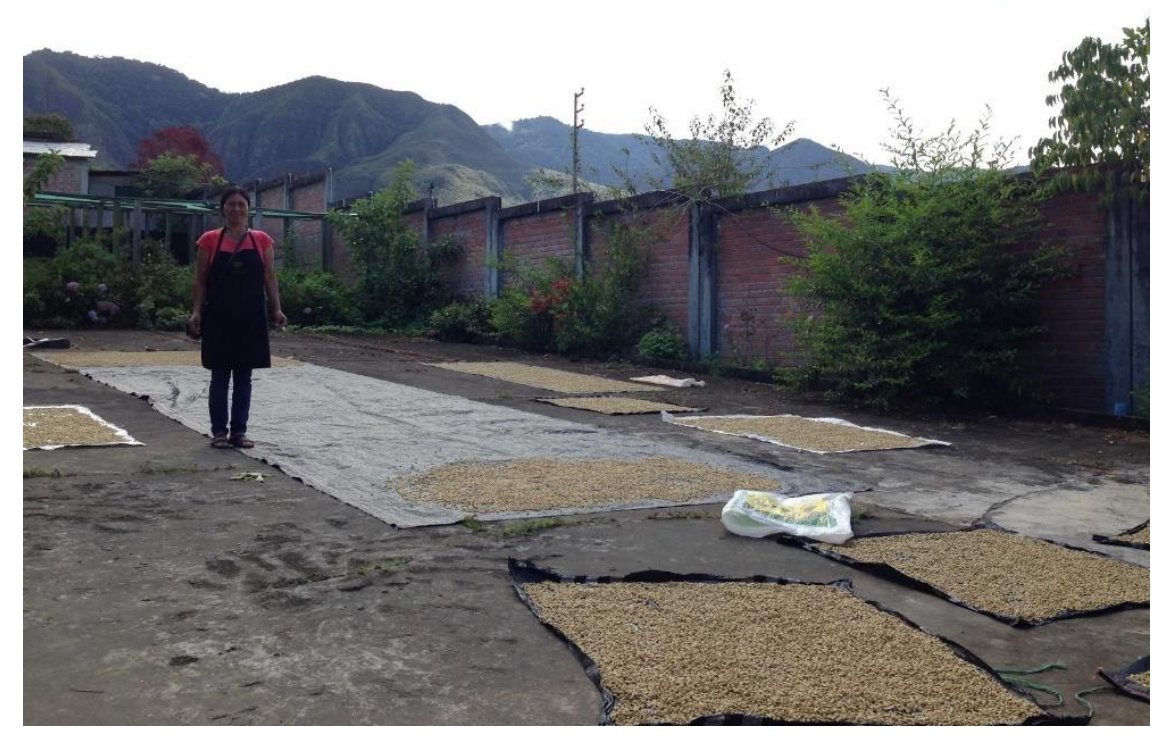

Figure 6 Coffee Growers Cooperative in Rodriguez de Mendoza

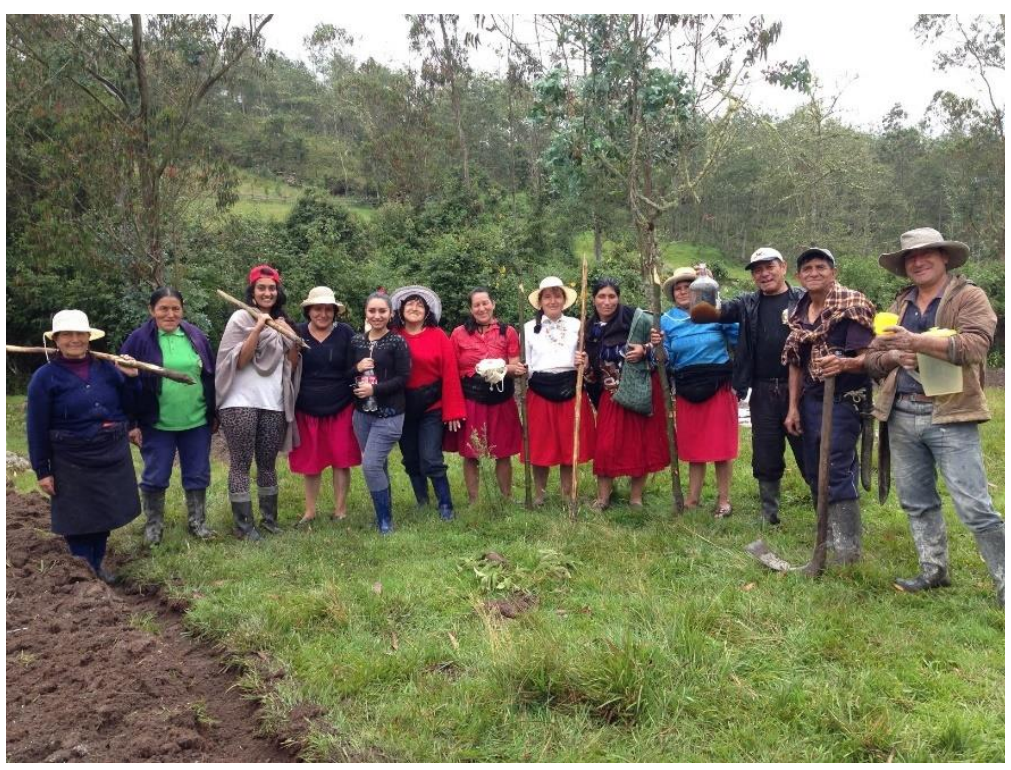

Figure 7 "Patara Minga," Quechua for Mandatory Work Day; Patara Specifically Referring to Agriculture in this Case 


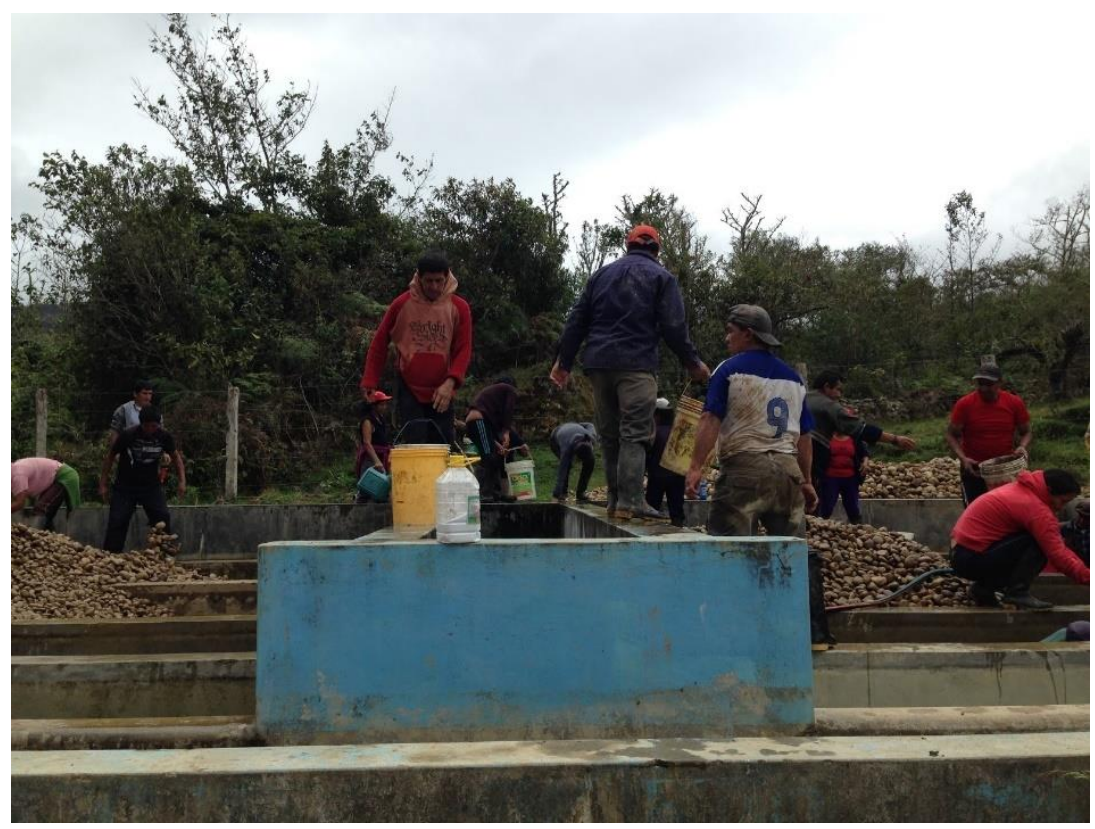

Figure 8 "Minga" for Rehabilitation and Maintenance of Water Filter

As a water and sanitation engineer, the volunteer and author participated in several collaborative projects with community leaders and organizations. Figure 7 demonstrates an example of a common practice in the community, patara minga, where community members collectively participate in sowing crop. In Figure 8, the community is participating in another type of minga, also known as faena or obligacion; in this case specifically related to water system maintenance and rehabilitation of filters. The author worked with water committees and local government in creating low cost chlorination systems for the reservoir of multiple rural communities, sanitation and water projects providing newly piped water and sanitation systems to the rural community of Huishcabamba, and participated in several other activities including community education related to environment and gender justice. 


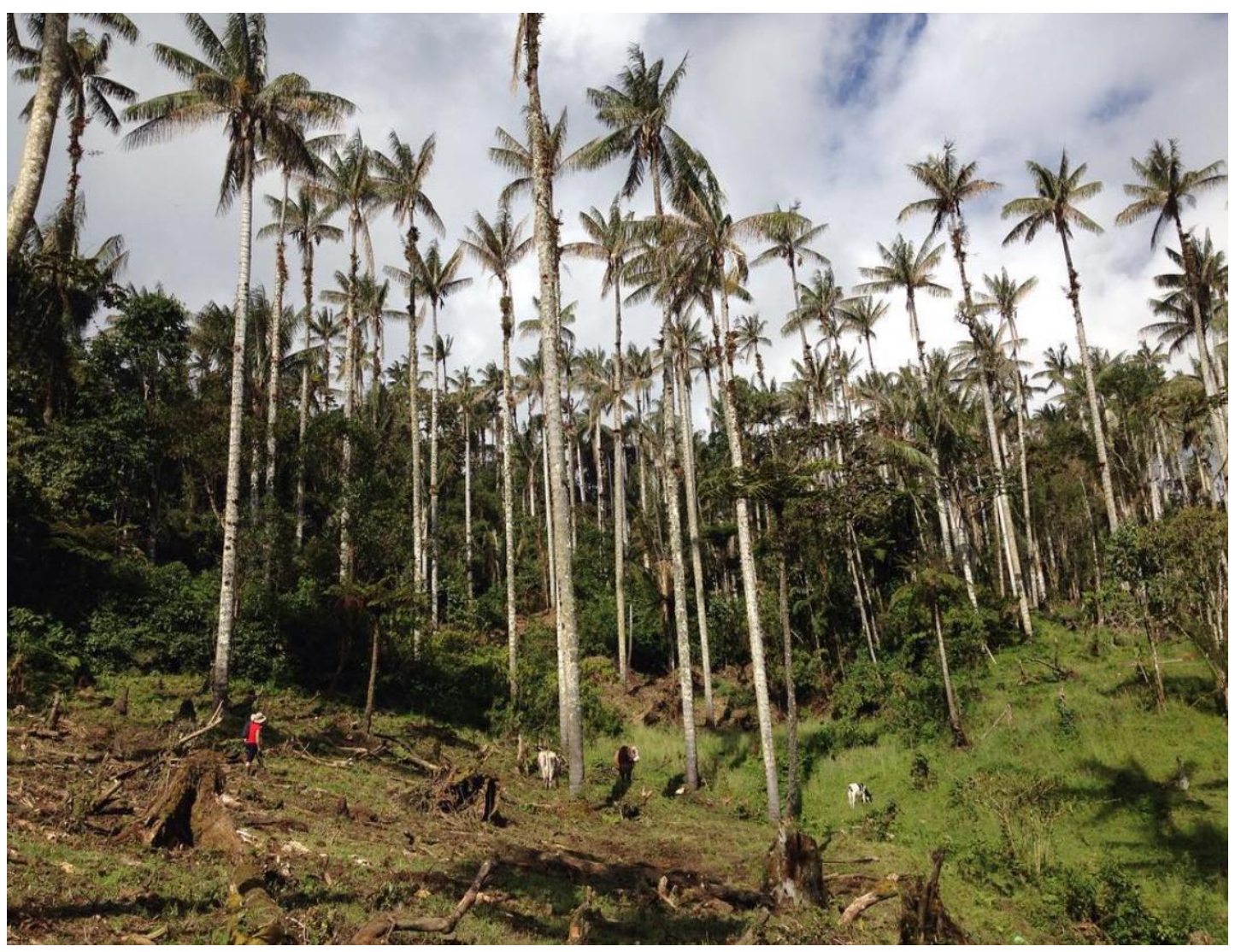

Figure 9 "Bosque de Palmera" the Only Palm Forest of its Kind at 2,300 meters ASL 


\subsubsection{Development in Molinopampa 2000 to 2019}

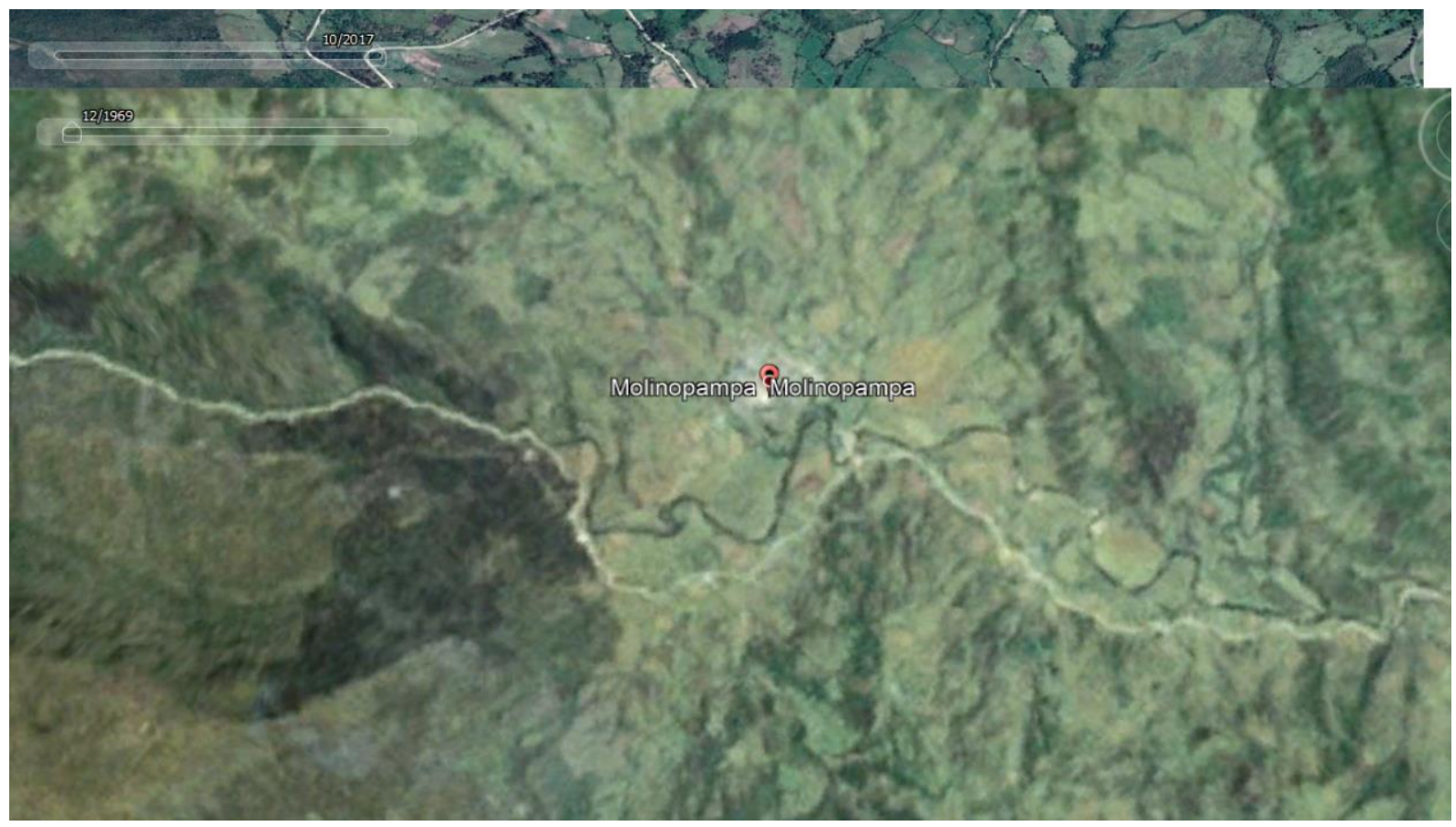

Figure 10 Molinopampa, 2000; Image from Google Earth 2019

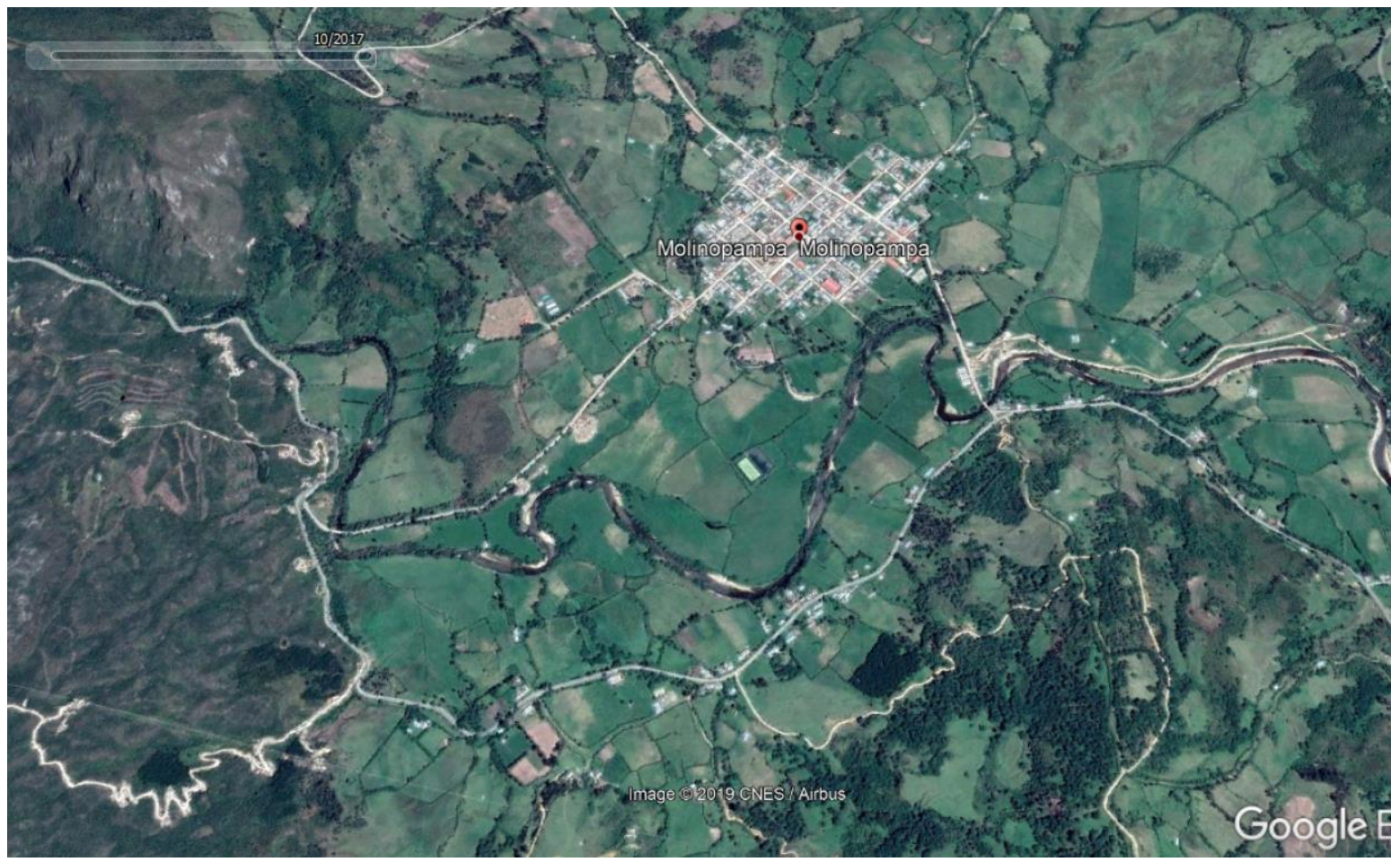

Figure 11 Molinopampa, 2014; Image from Google Earth 2019 
Development and paving of roads and a central highway that connects Chachapoyas to Mendoza and north east to Granada in the early 2000s changed the landscape and community dynamics forever. In 2014 a general contracting company, Selegsa, began the expansion of the electricity grid from Mendoza to Brazil through Molinopampa which has had measurable detrimental social and environmental impacts. Development of roads and highways since the early 2000s as well as the recent grid expansion have had an impact on water quality. Water quality has deteriorated at the source due to land erosion from deforestation and paving of mountain roads. According to the local health center, an increase in teenage pregnancy and assault was seen between 2015 and 2017 due to influx of Selegsa employees stationed in Molinopampa -most of which are from outside of the community. The installation of high voltage towers and creation of roads have also forced many farmers (in Molinopampa and all regions affected by grid expansion) to give up all or parts of their land for unfair prices. $90 \%$ of the district of Molinopampa do not have checking or savings accounts, vehicles, or other investments; typically, their home and their land are investments they own -usually inherited from previous generations. If PV technology was more accessible and popular, there may not be a need to expand the grid and many of these detrimental social impacts could be avoided. Decentralization of power generation empowers users, so they are not dependent on government or enterprises for electricity such as in this case. PV technology -if made more accessible- can close the gap on electrical connectivity when a community or individual desires. 


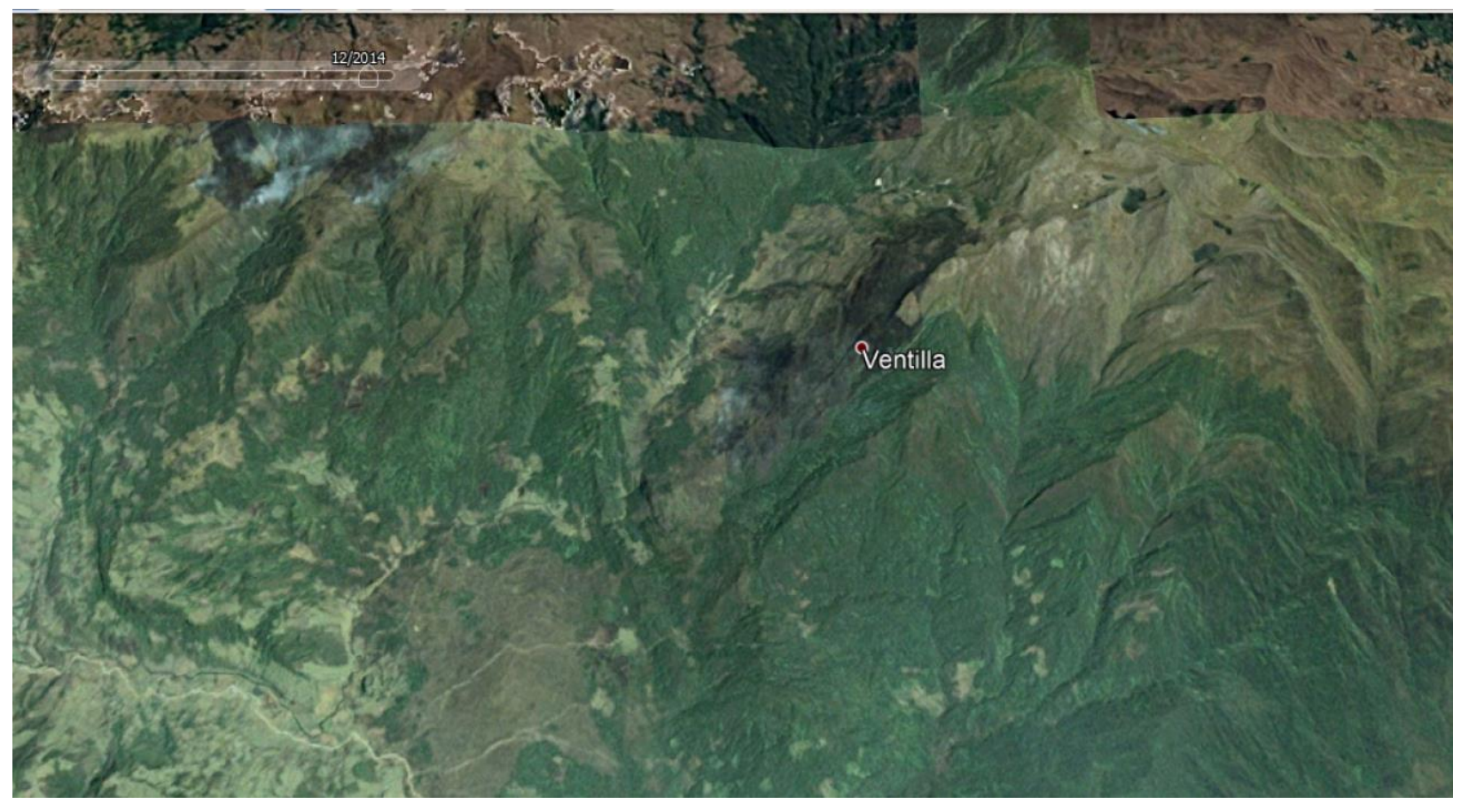

Figure 122013 Prior to Arrival of Selegsa; Image from Google Earth 2019

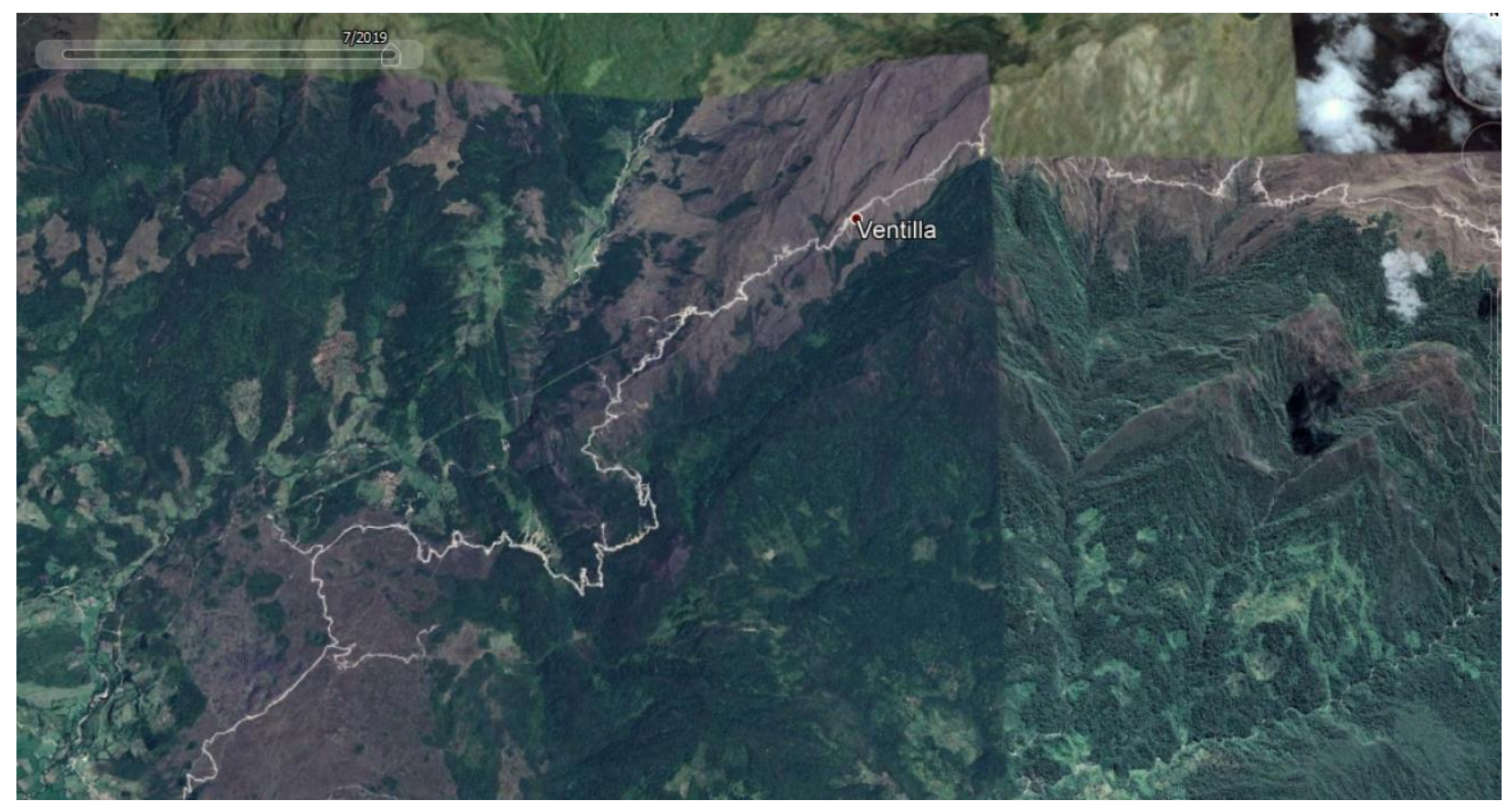

Figure 132017 Two Years After Arrival of Selegsa; Image from Google Earth 2019 
Figures 13 and 14 show the same rural annex Huishcabamba, of Molinopampa. Shown is a walking path that has existed for at least a century that connects Molinopampa to the high jungle and neighboring capital city, Moyobamba, through an annex known as Ventilla. The walking path is faint in Figure 13 and connects to the main highway. Figure 14 shows the walking path paved by Selegsa with excavators and other paving equipment between 2014 and 2017 including the removal of trees and brush; Ventilla and the surround region is pajonal or high wetlands.

\subsubsection{Solar Use in Molinopampa}

During the volunteer's time in Molinopampa between 2014-2017, several farmers in Molinopampa were using small 10W-20W PV panels to charge the electric fence around their cow pastures; there were no other uses of PV technology. Recently in 2019, due to a government initiative at national and state level, solar panels have been installed on resident's casa de campo. A casa de campo is a small farm house utilized when farmers visit their farms for the day or extended periods of time. These farm houses are usually located in the surrounded hills and mountains, one hour walk to several kilometers away. Some farmers travel all day by horse to reach their farm. The farm house is where they'll spend the day or weeks, cooking, resting, and as shelter during the rainy season. The panels produce enough electricity to power lightbulbs and two $220 \mathrm{~V}$ electrical outlets. All casa de campos are off-grid and until now, without electricity. This project only benefited those in the main town of Molinopampa and no other rural communities within the district; additionally, there are many homes in the district (in which families live permanently, not just farm houses) without electricity. Hundreds of new homes are being built in the last five years due to an influx of families from the 
neighboring state of Cajamarca where gold mining has polluted water sources, the district is growing and most of these new rural homes do not have electricity.

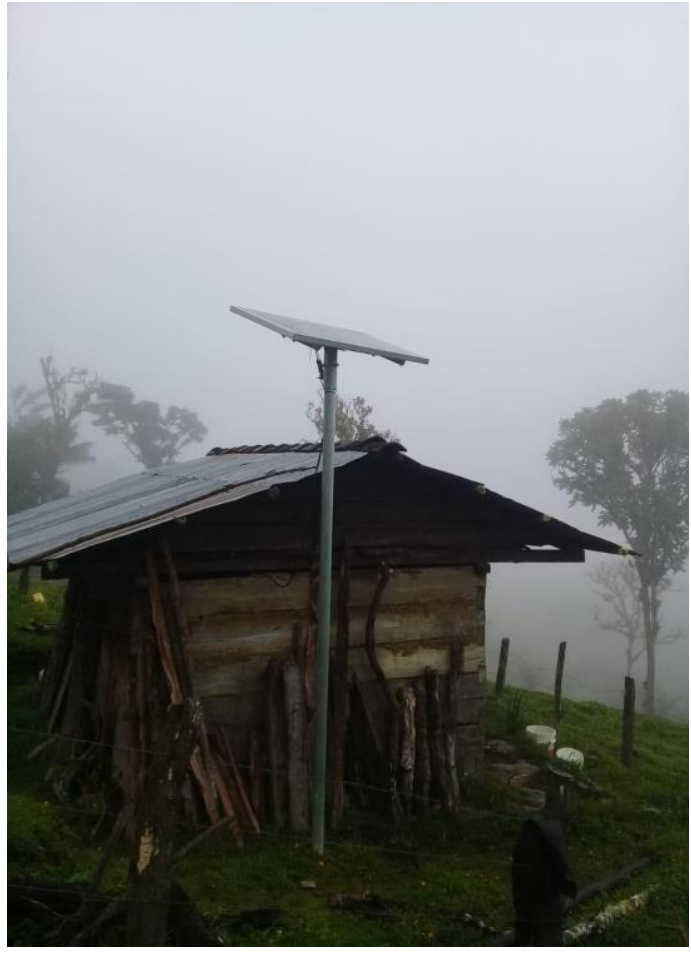

Figure 14 Casa de Campo, farm house, with newly installed solar panel

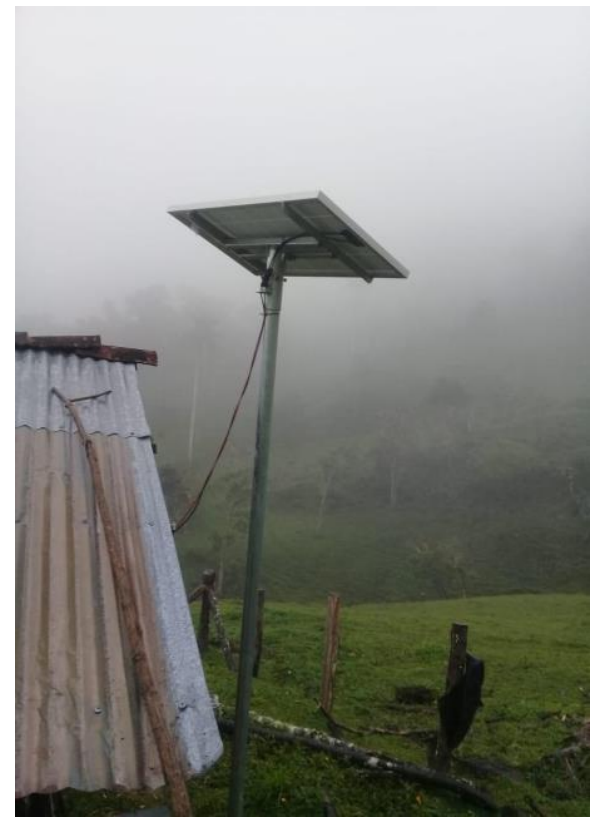

Figure 15 Panel is pole mounted 

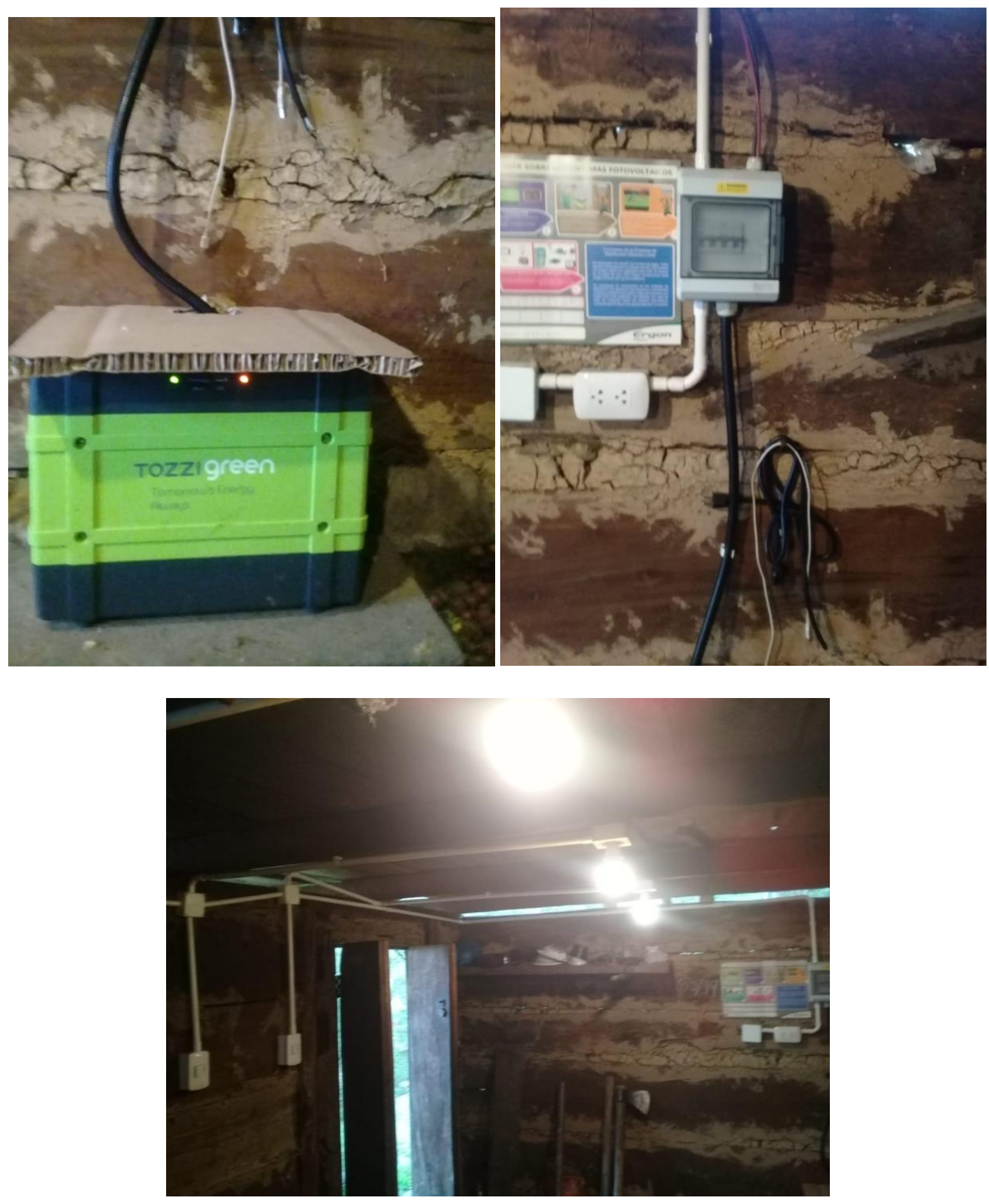

Figure 16 PV system equipment inside casa de campo 


\section{Literature Review}

\subsection{Wind Loads on Roof \& Ground Mounted PV}

Aerodynamic loads on solar panels and their structures are important to characterize and understand in order to guide PV industry standards and ensure PV panels are not compromised, set design criteria of rails and racking to which modules are secured so racking systems are not under or over designed, and to ensure building roof load capacities are not exceeded. Several studies have been published on aerodynamic effects of roof-mounted PV systems. Rooftop PV systems may change the building profile and add additional wind and snow loading. Some studies have shown that sheltering effects from the building can change wind load profiles, and in some cases lower them on certain modules within a system. Ground mounted arrays have unique wind loading effects that also require structural considerations. Aerodynamic effects are critical in megawatt solar farms where modules are stacked tall and wind loading is of more obvious concern. However, wind loads should be considered in small, domestic PV applications such as single or multiple pole mounted or ground mounted backyard systems. Currently, many residential and commercial PV applications (roof or ground) rely on the same racking systems and proprietary rails that are designed for extreme wind loads. Understanding wind loading effects on small-scale racking systems can help improve efficient design that is tailored to domestic applications and ultimately lower racking system costs.

There is a lack of literature on racking, for ground mount, fixed-tilt solar PV systems.

Literature that exists discusses mostly rooftop racking and installations and wind loading since building integrity is a public safety concern and governed by building code. American Society of 
Civil Engineers 7 (ASCE 7) provides standards for wind loads on various structures. ASCE 7 does not approve the use of computational fluid dynamics (CFD) to model and analyze wind loading on solar panels due to issues of obtaining accurate peak loads.

Buildings with PV installations may experience increased snow loads on roofs, and specific wind dynamics due to interaction between building edge and PV installation. While code requirements exist, there are no guidelines or industry standards provided for the unique geometry of roof or ground mounted PV. The 2016 California Building Code (CBC) Section 1510.7, 1613.6, and ASCE 7-10 Section 13.4 address seismic and wind accommodating requirements for roof mounted PV structures. The building code of California has few seismic requirements for ballasted roof solar panels determined by ASCE 7 and 7-10, but lacks specific details and guidelines for consumers to ensure their installation follows these requirements. ASCE 7-10 requires these systems be anchored, failing to address ballasted systems. Ground mounted systems are omitted altogether.

Building and PV arrays generate different loads, where arrays typically generate turbulence -a factor of tilt angle (Kop et al 2012). Turbulence dominates in higher tilt angle configurations, while pressure equalization dominates in low tilt angle configurations and the aerodynamic loads differ greatly between ground mounted and building mounted arrays. Critical wind directions differ between ground mounted and roof mounted arrays. For both arrangements, critical wind directions were northern and northern cornering winds. However, southern critical wind directions only affected roof mounted arrays, not ground mounted arrays, because of the building's southern edge effects. There are large scale building generated vortices that affect roof mounted arrays, but not ground mounted arrays. ASCE 7-10 may not 
take this into consideration, as the impact of the roof's edge on wind loading is much larger than the code implies. Northern winds were shown to be critical to both ground and roof configurations, but southern winds are only critical to roof mounted systems because of the uplift at separation bubble at building edge (Kop et al 2012).

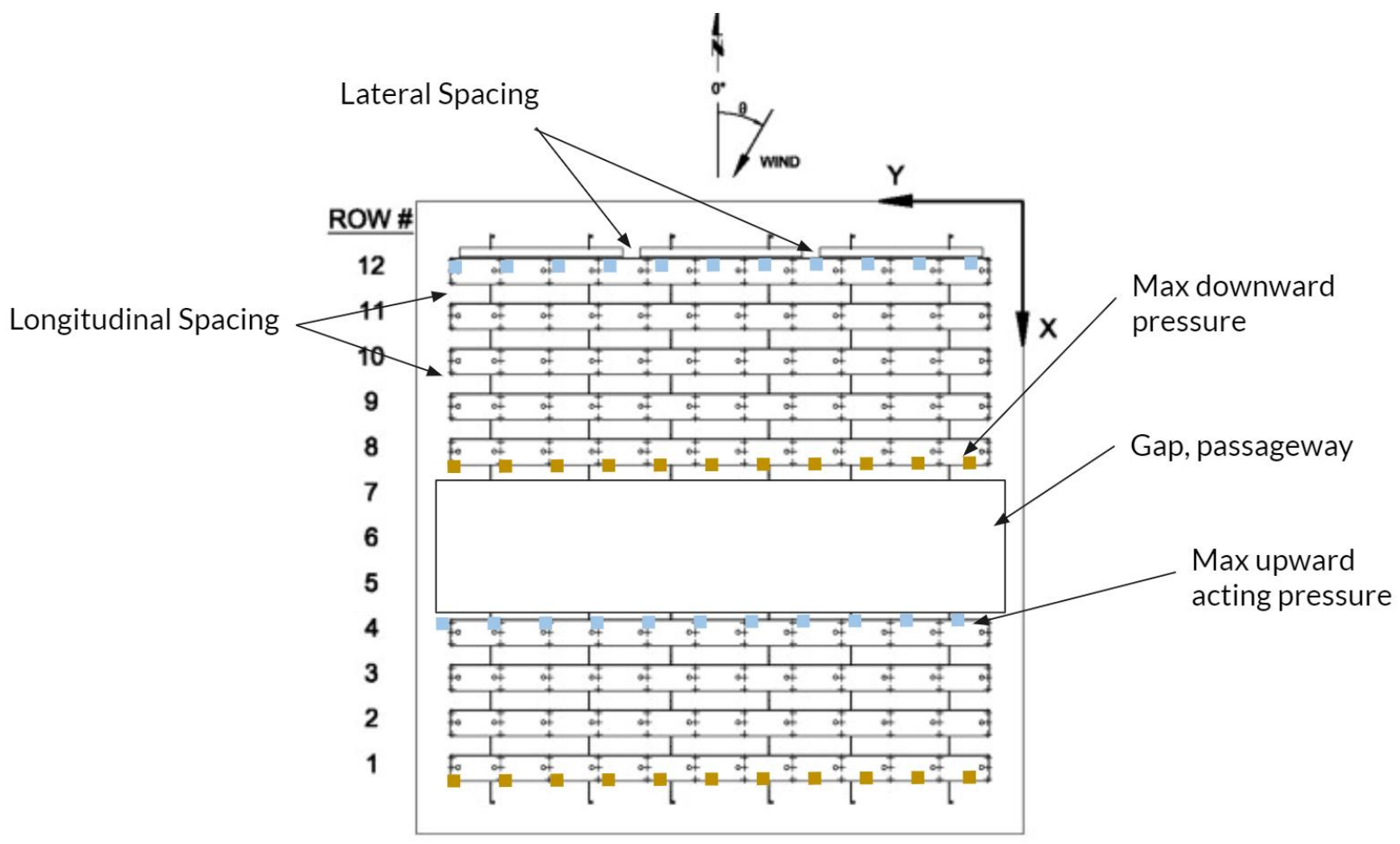

Figure 17 Effects of longitudinal and lateral spacing (Adapted from Kop et al 2012)

Figure 20 shows an arrangement of panels (Kop et al 2012) with a separation after the fifth row. Aerodynamic loads decrease downstream of wind direction along rows and are negligible by the fourth row. Modules making up the outermost columns (along the perimeter) experience higher loading than the modules inside the configuration. Lateral spacing between rows does not change wind load effects, but increasing longitudinal row spacing minimizes shelter effect, thus increasing aerodynamic loads (presumably, keeping longitudinal row 
spacing tight can increase shelter effect and decrease aerodynamic loads). Isolated modules experience higher wind loading than those within arrays. Additionally, wind loads decrease on roof mounted panels as the perimeter gap from building edge increased. The top surface pressure for ground mounted systems are positive, but for roof negative, meaning roof mounted experiences vacuum (suction/pulling) that ground mounted systems don't, due to building and leading-edge effects, because panels divert wind flow above panels downstream of wind flow (Warsidio et al (2014)).

Reina et al (2017) notes only until recently most studies have been performed on roof mounted arrays. They studied improvement of modeling of aerodynamic loads on ground mounted arrays to reduce computation costs. It is noted that WTT and modeling of ground mounted is challenging because of the very small-scale requirement. This study uses CFD on tracking (rotating with respect to sun angle) ground mounted arrays. The entire system and a portion of the system ("the reduced periodic model") were modeled at different tilt angles and it was found that the results from the reduced model are acceptable for analysis of the entire system, lowering computational time and cost. Additionally, aero loads due to rotational tracking (horizontal axis) were dynamically analyzed and compared to static analysis at distinct tilt angles, altogether resulting in reduction of computational costs.

Stathopoulos et al (2014) conducted an experimental study to understand pressure distribution on stand-alone flat panels at different tilt angles and proposed GCp coefficients for design of ground and roof mounted panels. They found panel inclination is significant only for the critical wind direction to be of 135 degrees, (but increase between 105-180 degrees). Back 
located panels on building experience higher suction (negative pressure), and the most significant net force coefficient occurred with panels situated along the edge of the roof.

Abiola-Ogedengbe et al 2015 confirmed findings from Warsidio et al 2014 that inter panel gap -important in large systems- affects the surface pressure field. Additionally, module or system orientation with respect to wind direction affects inter-panel gap influence on surface pressure of panel. They confirmed there is an increase in pressure as tilt angle increases. Smooth wind exposure vs open terrain wind exposure effect mean pressure magnitude on PV module (with the former causing increases).

Somekawa et al 2013 is the only one to study wind loads on racking system (and panel). Maximum downward wind forces were experienced along southernmost panels within the testing configuration as well as the western edge for all panels in the configuration. Spatial arrangement has significant effect on forces depending on panel location with respect to spacing. In the case there is a separation in array configuration, the panels north of the separation, but still southmost in their configuration, experience peak wind loads; this is most likely because of the lack of sheltering effects from the rest of the arrays because of the gap. In staggered arrangement, western and southern edges experience the greatest force because of lack of sheltering from surrounding panels. Maximum uplift ("negative" upward force) is experienced by all panels in all configurations on the northernmost edge, but in the back row, uniformly across panels. Sheltering does not seem to apply for upward wind forces. Panels along perimeter and separation gap can be treated the same way in design considerations. With respect to PV support structures, a difference in wind loading on shorter and longer support columns was noticed. Greater tilt angle panels experience greater upward (neg/uplift) 
wind forces. Pressure coefficient varies greatly when non-uniform wind loads are applied -they experience greater uplift, especially along longer columns.

Wind tunnel testing (WTT) require design and models with geometric scales of 1:500 to 1:100 Aly et al (2013) which is why WTT testing has been mostly performed on roof mounted PV that can be accurately modeled using this very large scale. However, this is too large of a scale to dimension ground mounted PV and would make the modules too small resulting in WTT challenges for accurate modeling (Aly et al 2013). Analysis is still required to characterize wind and panel interactions at the ground.

\subsection{Alternative Racking Systems: Current Research and Design}

Recent work in PV racking systems aim to study material use and manufacturing methods. Wittbrodt et al (2017) used the ReRap 3-D printer to print and test an alternative racking system in harsh winter weather conditions. The customizable, open-source racking system maintained structural integrity under harsh weather conditions (snow, temperature, wind) and was found to cost only $10-15 \%$ of commercial racking systems if using PLA and HDPE plastics, respectively (economically compared to UNIRAC RM and strength of Al vs PLA). The alternative 3D printed rack ultimately resulted in $80 \%$ reduction of cost compared to conventional off the shelf racks (Wittbrodt et al 2015). Alternative options include printing with the Recyclebot when appropriate waste plastic options were available. This is the first time a study has been conducted on cost evaluation of PV racking system. This method of solar racking manufacturing is extremely critical in holistic approach to sustainable engineering solutions and appropriate technology, when waste plastic can be used instead of depleting natural resources. 
Wittbrodt et al (2015) observed feasibility of decentralized (distributed) manufacturing through the use of the RepRap 3D printer, specifically for recreational vehicle (RV) applications, with customizable tilt angle. A $20 \%$ increase in electricity production was observed due to tilt angle adjustability, and significant cost decrease resulting in USD 7.21 system cost or USD 0.036/watt system Wittbrodt et al (2015).

Pearce et al (2017) developed a modification of roof and BIPV PV racking that resulted in a cost decrease of $20 \%$ from conventional racking and $90 \%$ from BIPV (USD 22/module cost of this design). The racking system was building integrated to accommodate a conventional PV module.

\subsection{Existing Racking: Companies and Off-the-Market Racks}

Solar racking is marketed for extreme loading conditions for large megawatt farms and corporations. Because of the lack of literature and guidance on DIY racking systems, PV consumers are forced to rely on expensive, overly designed off-the-shelf racks or rely on costly installation packages. Commonly used brands are IronRidge, Unirac and Snapnrac. These companies use proprietary designs, especially for their rails with unique cross sections (Figure 19-20). When using their system users are required to purchase their brand of products. They offer proprietary splices to extend rails and proprietary mounting hardware and fasteners (Figure 21). The IronRidge website demonstrates their curved rails withstand $4500-9000 \mathrm{lbf}$ of lateral loading with a factor of safety (FOS) of 2 (Figure 18). 


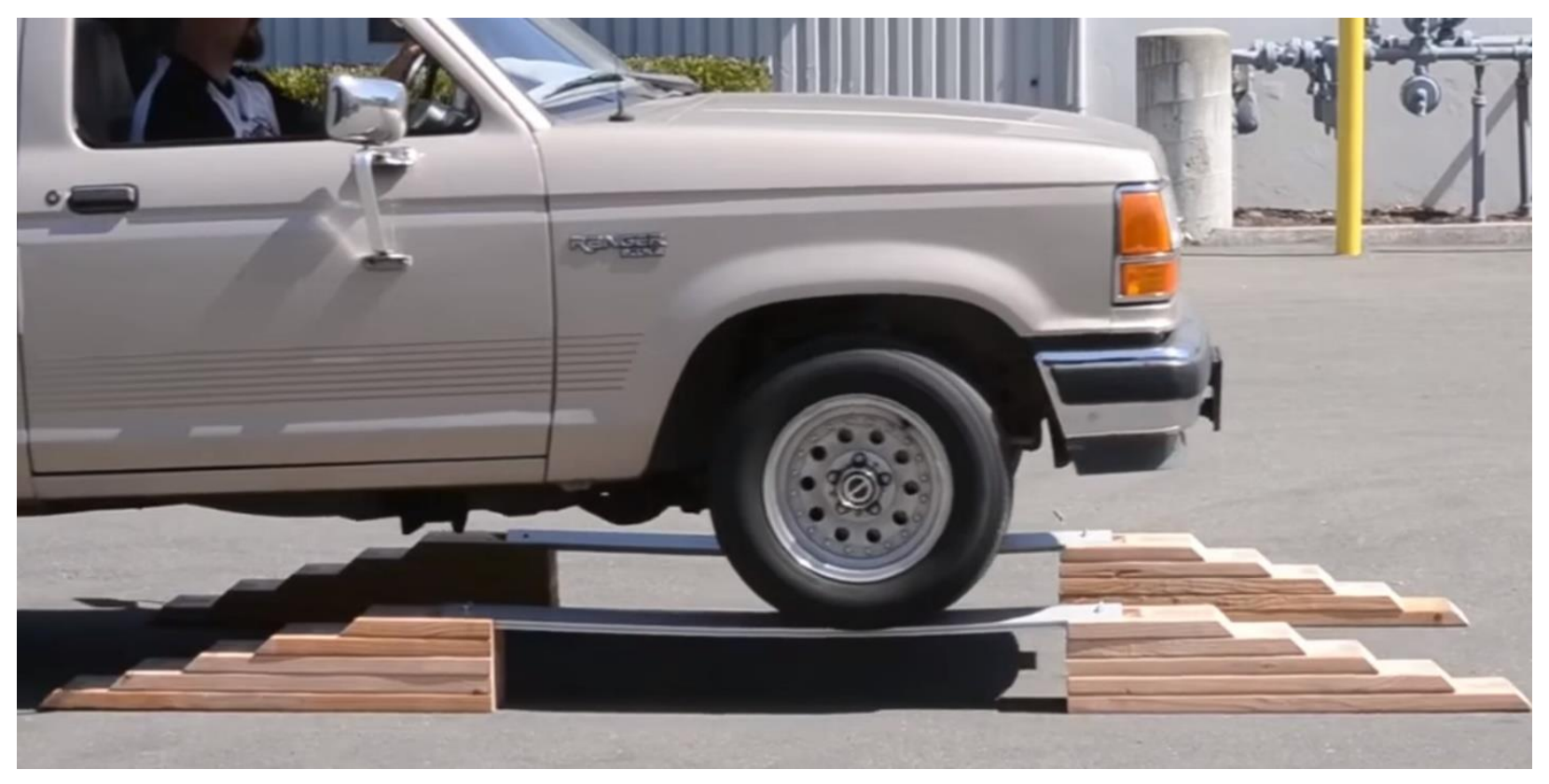

Figure 18 IronRidge tests their proprietary rails against "boxed" rails (from IronRidge.com)

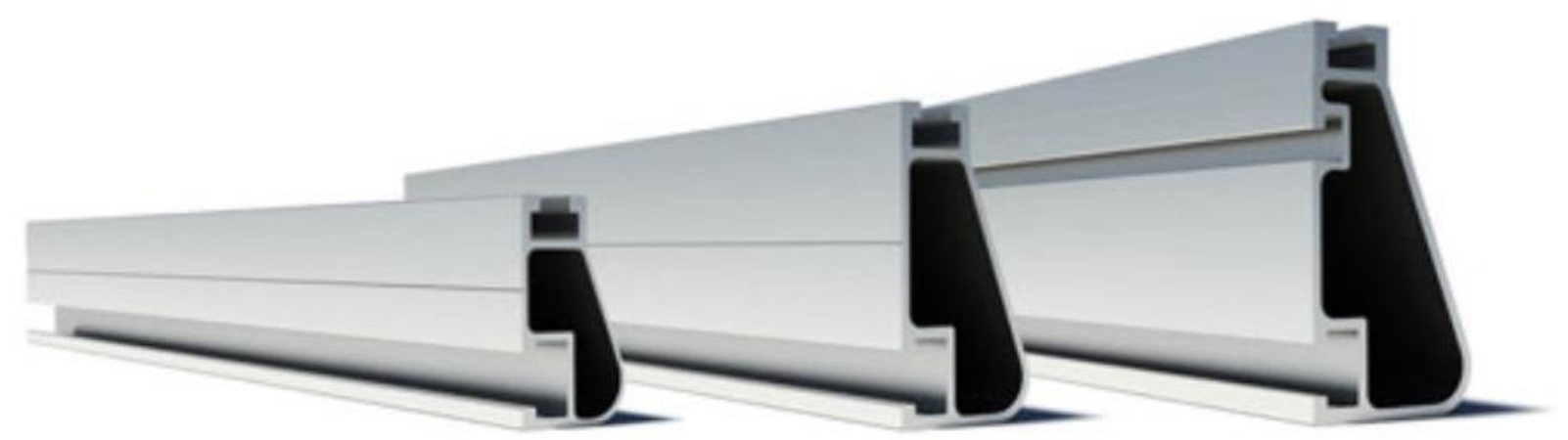

Figure 19 IronRidge XR Rail Series from Ironridge.com 


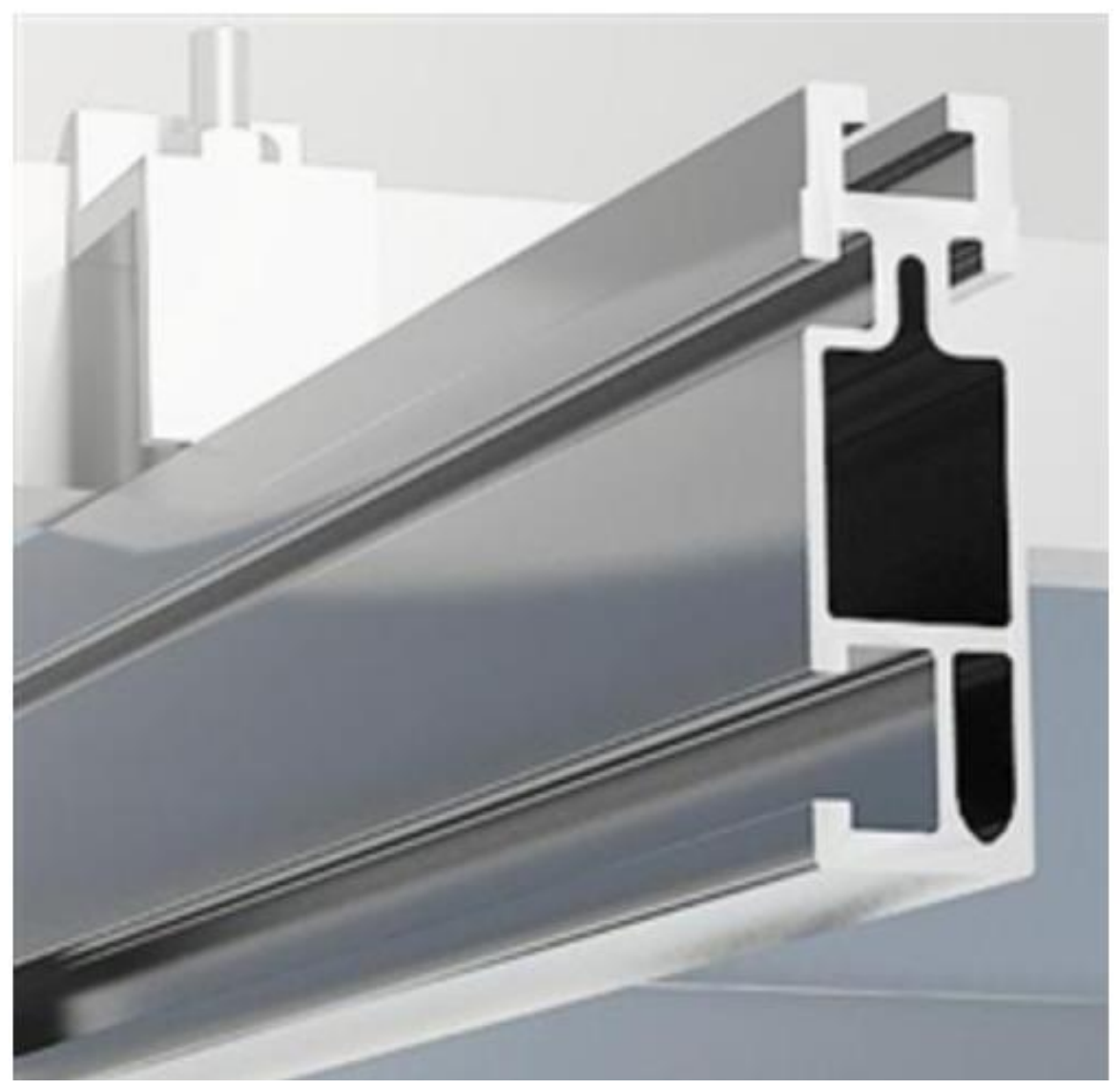

Figure 20 Unirac Proprietary Rail from Unirac.com
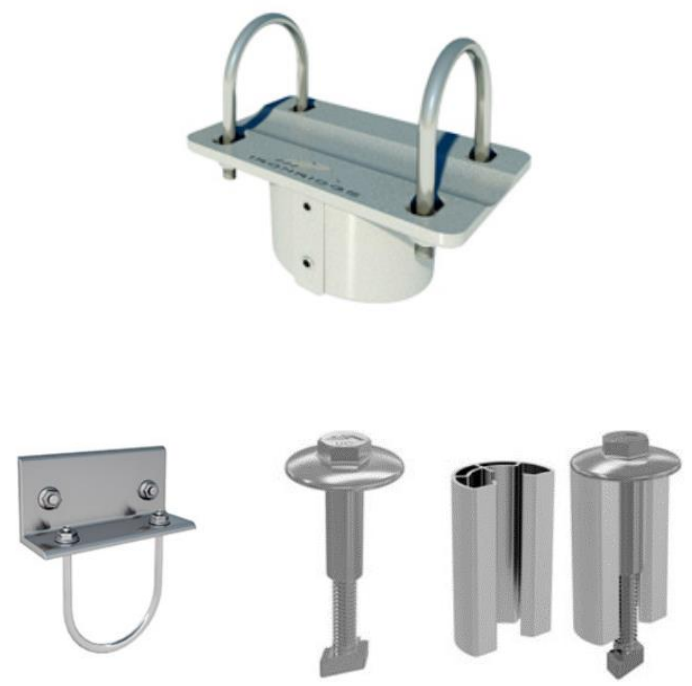

Figure 21 Fasteners and Mounting Hardware from IronRidge 


\subsection{Design Considerations for PV System}

The following general steps are necessary to consider in designing a DIY PV system.

1. Assess user energy needs to obtain number of modules required. Every user will have different energy use needs.

2. Understand installation latitude to set appropriate tilt angle; determine if adjustment throughout the year is necessary and feasible.

3. Account for all possible external loading: in most cases this will be wind and snow. Look up values applicable to site of installation, available in building codes and local jurisdiction (Figure 23-25).

4. Account for total system weight (modules and structure).

a. Typically, module size: 70 in $\times 40$ in, $40-50$ pounds per module

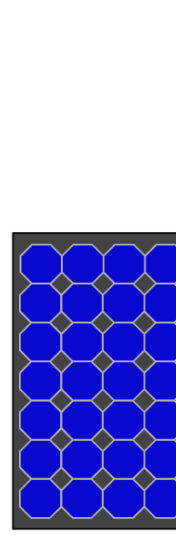

Module

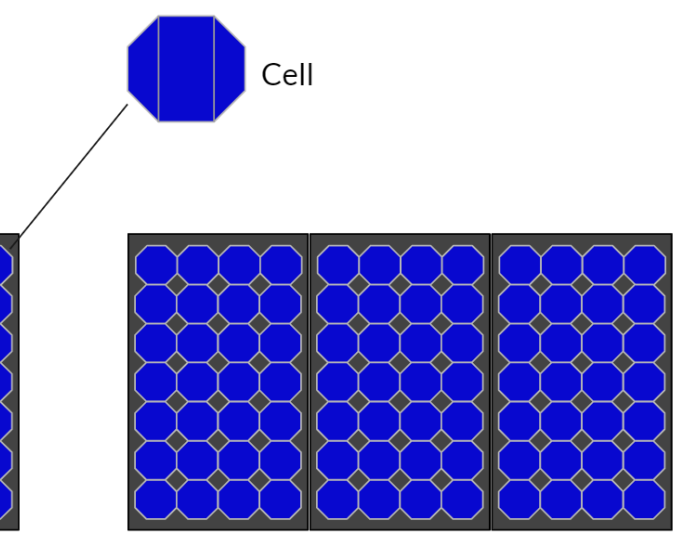

Panel

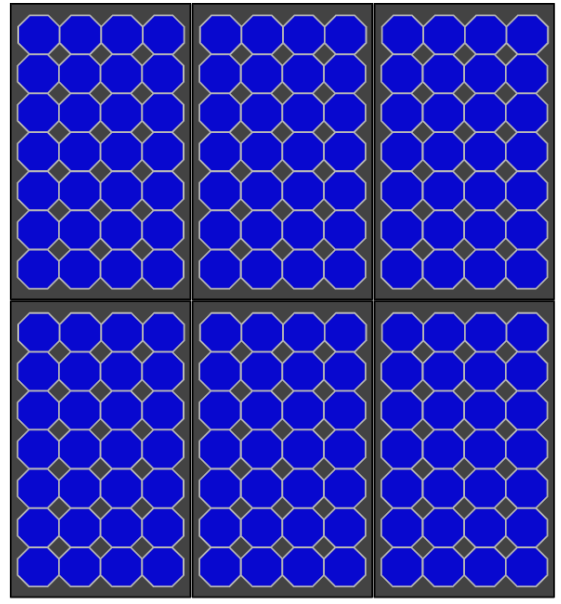

Array 


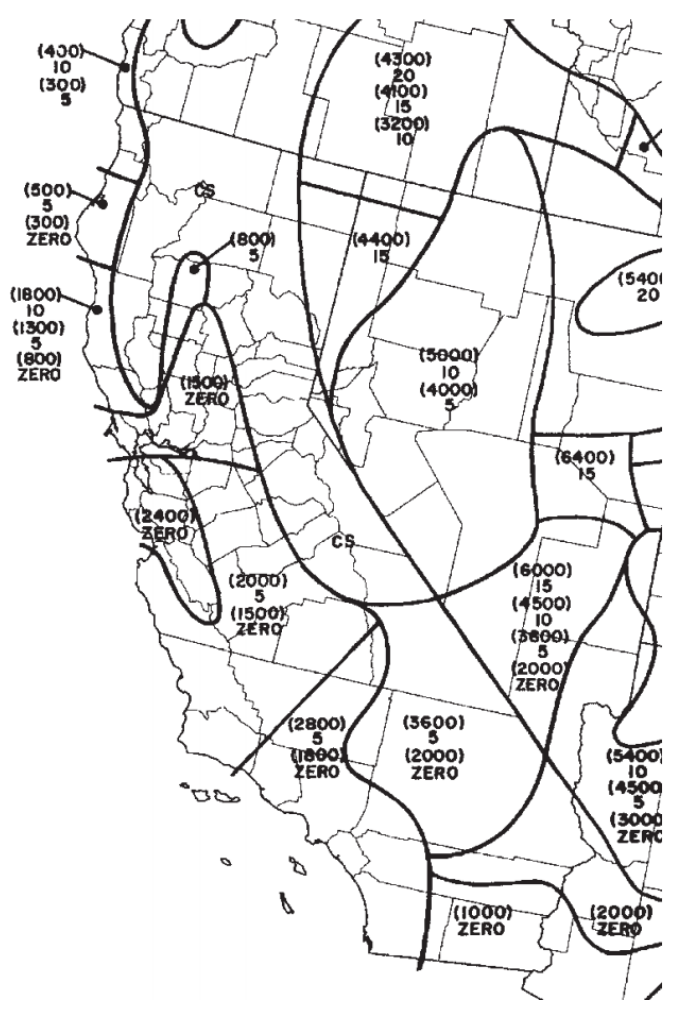

Figure 23 Ground Snow Load (PSF)Map (from ASCE 7-10)

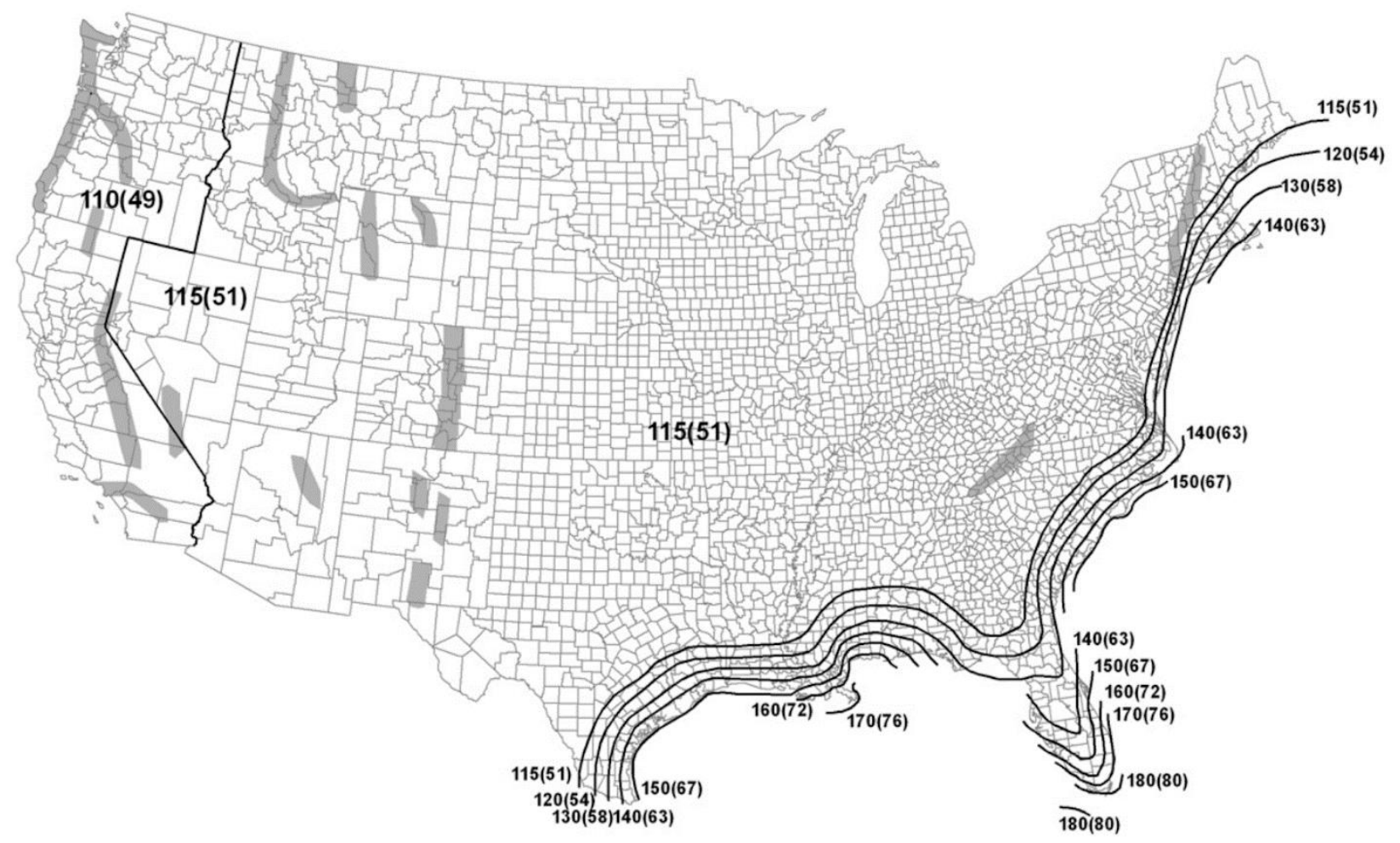

Figure 24 California Design Wind Speed(MPH)Map (from ASCE 7-10) 


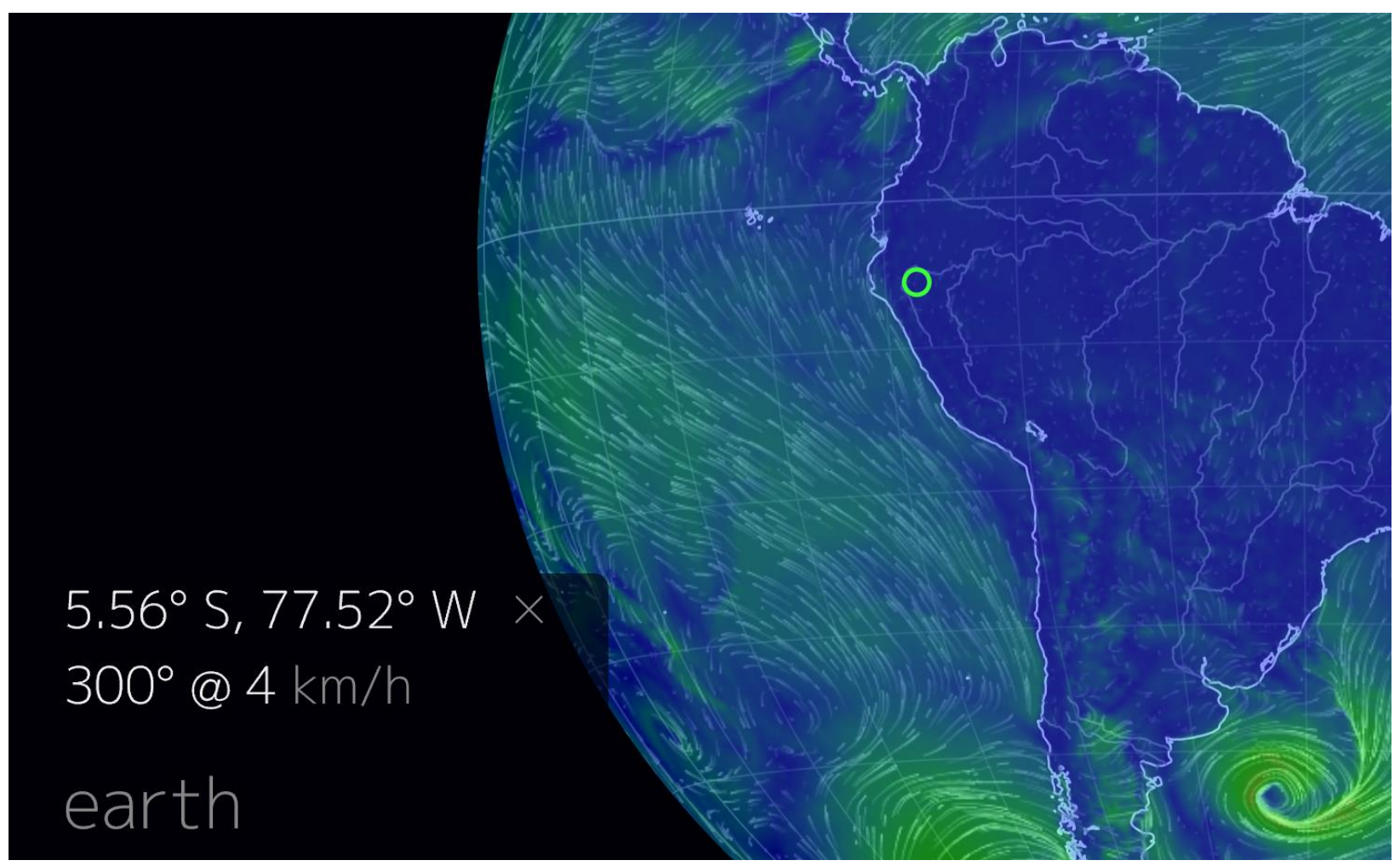

Figure 25 Wind speeds around the world (earth.nullschool.net)

\section{Methodology for Analysis}

\subsection{Outline of Steps}

First, a static analysis of a DIY structure is provided at various tilt angles for three different materials. Then a cost analysis is provided for various PV racking systems and package installations from popular manufacturers and solar installation companies and compared with that of the sample DIY PV system. Material properties for possible racking material candidates is provided. 


\subsection{Load Considerations}

\subsubsection{External Loads}

The DIY PV system presented will primarily experience wind and snow loading forces. The weight of the system must be taken into consideration as well. Wind loads on PV installations can be calculated as a pressure load on the system when wind speed and area acted upon are known (in this example, the area of one module is taken into consideration). If the PV system is installed in an area that experiences snow, snow loads can be represented as distributed weight loads across the structure's surface. The principles of static analysis depend on the following two equilibrium equations:

$$
\begin{aligned}
& \Sigma \bar{F}=0 \\
& \Sigma \bar{M}=0
\end{aligned}
$$

The sum of the forces are zero and the sum of the moments are zero; that is, the structure should be designed to resist loading and deformation.

To calculate wind load from known wind velocity, v:

$$
\mathrm{F}_{\mathrm{w}}=1 / 2 C_{d} \mathrm{~A} \rho \mathrm{v}^{2}
$$

Where $C_{d}=1$ for non-aerodynamic PV structures and $\rho$ is the density of air. $\mathrm{A}=$ Area module $\sin \theta$, where $\theta$ is the tilt angle (see Figure 28)

The area of the module is the areal area opposing the wind force and a function of tilt angle 


\subsubsection{Boundary Conditions}

Different types of connections are used to support certain loads. Structural supports make connections between structural members that allow, support, and prevent specific movements and loads. Common types of support include: pin, roller, and fixed. Each type of support exerts a reaction (force). Pinned supports exert a vertical and a horizontal reactive force, roller supports exert a vertical reactive force, and fixed supports exert a vertical and horizontal force, as well as a moment. Supports are chosen based on the type of loading desired to be prevented.

There are several support options and constraints for PV racking systems. The rack may be ballasted with concrete blocks along the bottom rail -this applies to both ground mounted and roof mounted structures. Members along the perimeter or corners of the structure may be mounted within concrete piles in or above the ground, or with the use of steel brackets. In many cases, the weight of the structure, supports, and panel is enough to sustain and resist external loads.

\section{Analysis and Results}

\subsection{Equations for Static Analysis on Structure}

Static analysis of the PV structure will provide resulting internal forces and anchoring (if required) for a system based on external loads. For the following DIY structure (Figure 26) and PV panel (Figure 27) symmetry is used and static analysis is applied to half of the structure; half of the structure experiences only half of the external loading (Figure 28). 


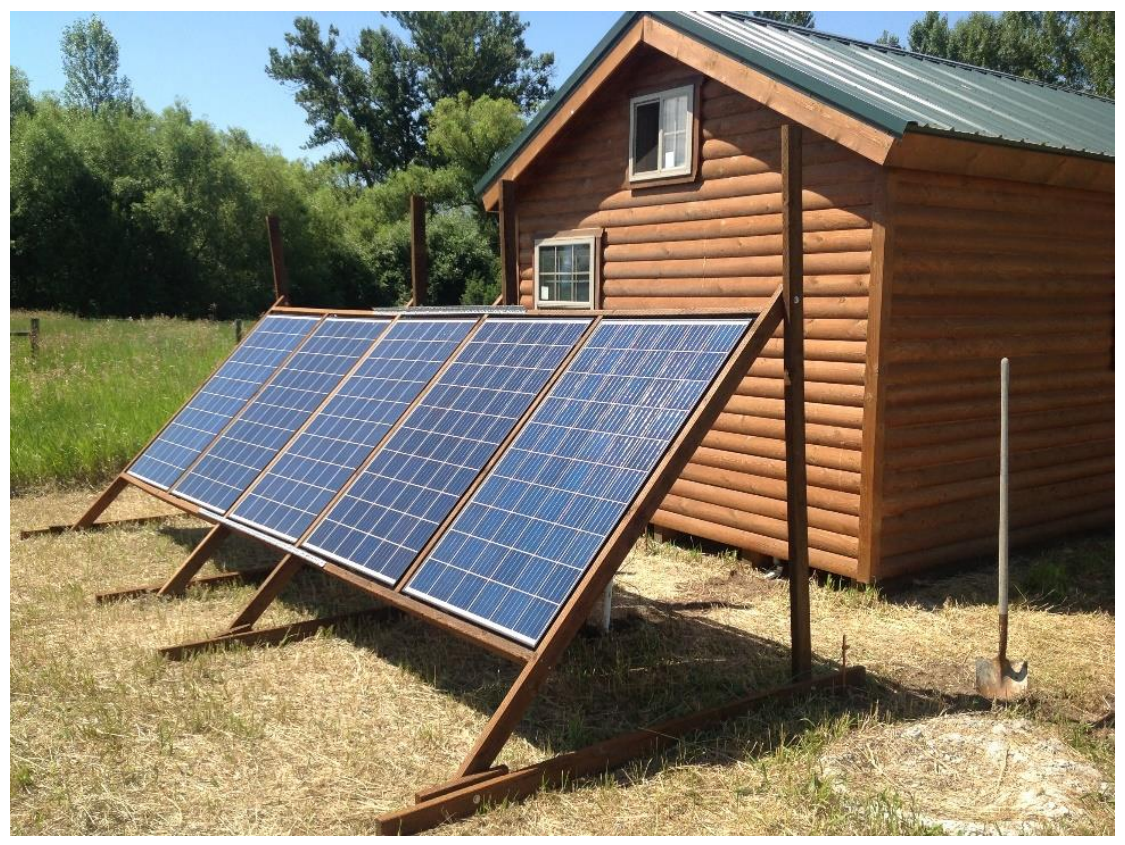

Figure 26 DIY structure designed and installed by Dr. Craig Friedrich (Montana)

\section{Rear View}

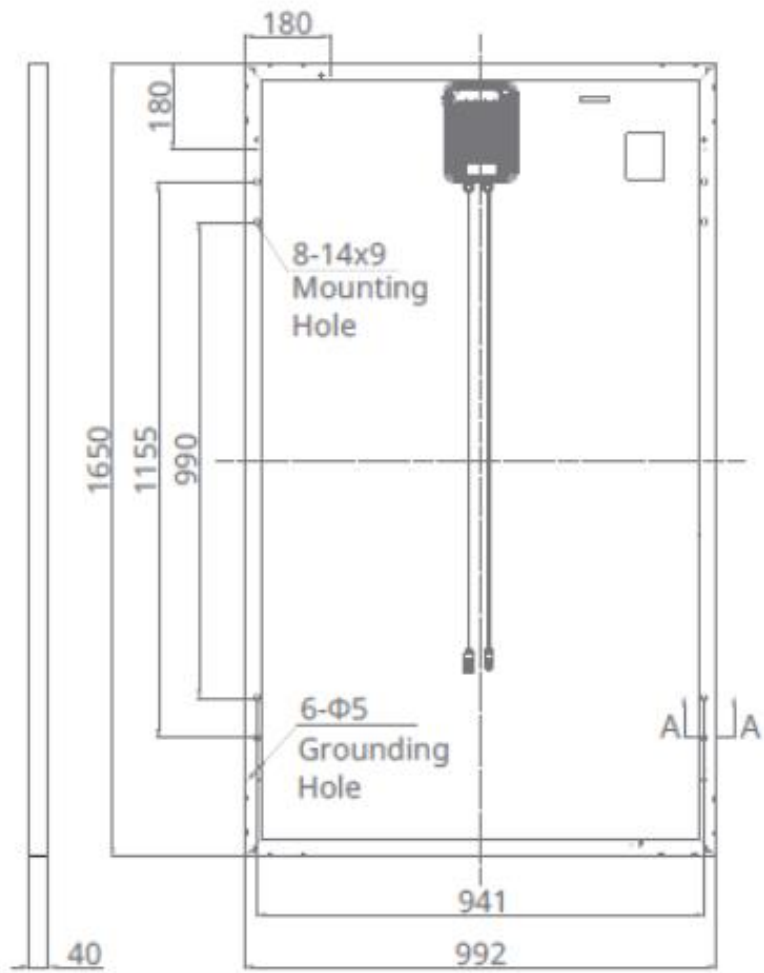

Figure 27 Module dimensions used in analysis (typical dimensions) 


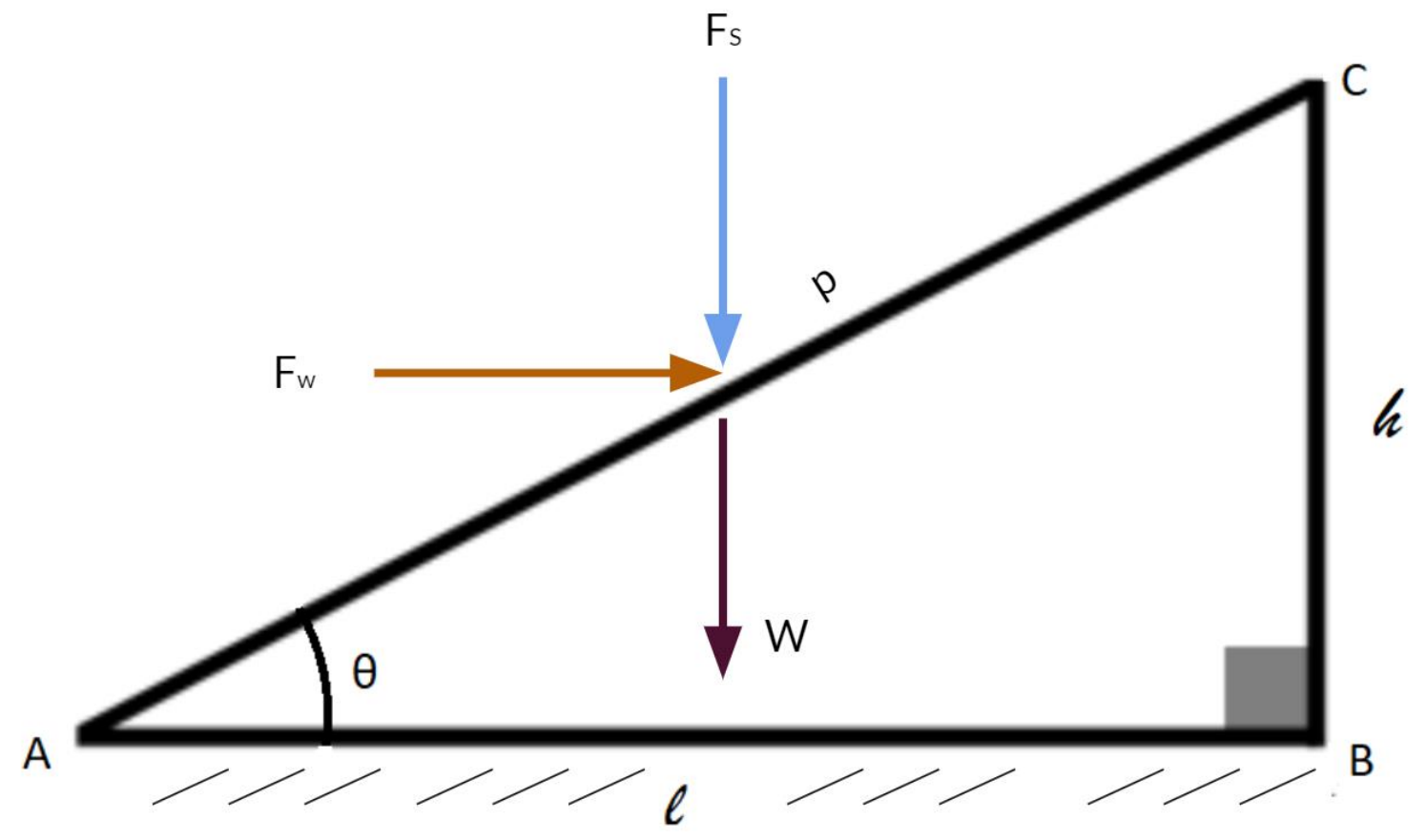

Figure 28 Free body diagram of half of the system. Note, all external loading applied to this section will be half of their total value on the system.

Analysis will be provided on half of the system in figure 28. $\mathrm{P}$ is the panel length of the module supported by the hypotenuse of the structure and:

$$
\begin{aligned}
& l=p \cos \theta \\
& h=p \sin \theta
\end{aligned}
$$

Analyzing the moment about A in member AC provides values for compressive loading on member BC. The following equations are obtained (Figure 29): 


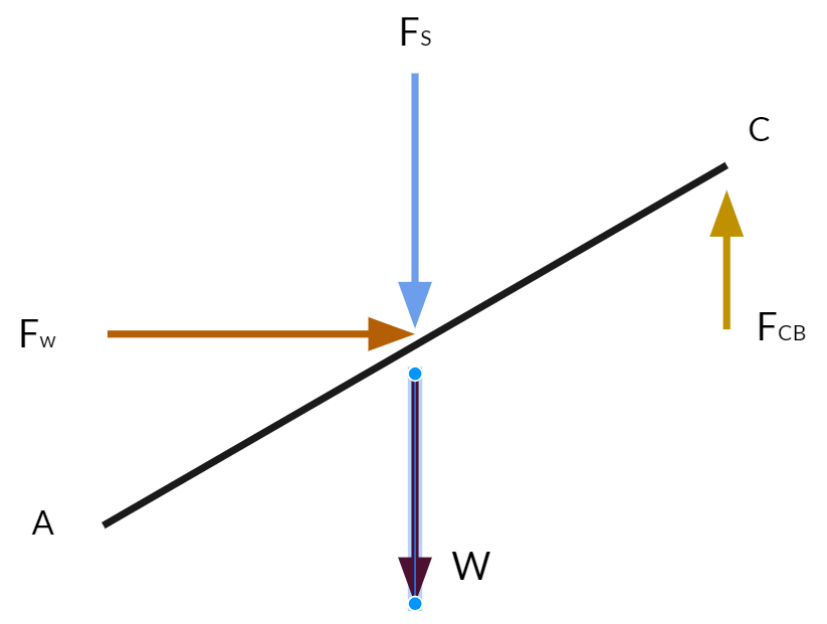

Figure 29 Structure $A B C$ is broken into its component; the sum of the moments about $A$ is taken for member AC.

$$
\begin{gathered}
\sum M_{A}=0 \\
-\left(W+F_{S}\right)\left(\frac{l}{2}\right)-F_{w}\left(\frac{h}{2}\right)+F_{C B} l=0 \\
F_{C B} l=\left(W+F_{S}\right)\left(\frac{l}{2}\right)+F_{w}\left(\frac{h}{2}\right) \\
F_{C B}=\frac{1}{l}\left[\left(W+F_{S}\right)\left(\frac{l}{2}\right)+F_{w}\left(\frac{h}{2}\right)\right]
\end{gathered}
$$

To obtain the cross sectional area of member CB that will withstand the compressive loads, the following equation can be used: The compressive column loading in $\mathrm{BC}$ an be used in 
conjunction with maximum allowable stress of the material to obtain cross sectional area of the beam

$$
\sigma=\frac{F}{A}
$$

Now, the bending moment of member AC must be observed. Member AC should resist bending so the PV panel does not break. Obtaining maximum moment on the member also allows for calculation of the beam cross section.

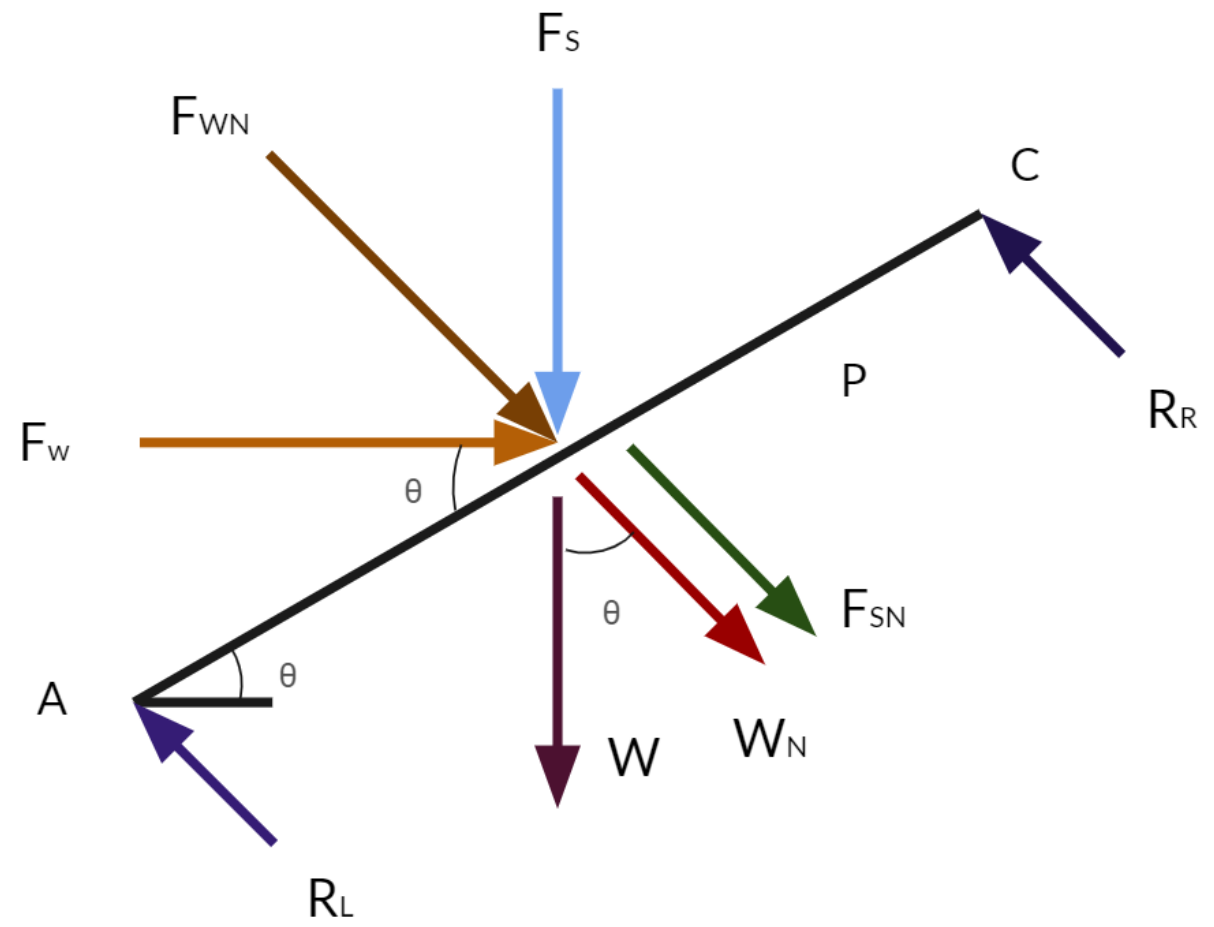

Figure 30 Analyzing equivalent normal foces on AC to obtain maximum moment

$$
\begin{gathered}
F_{W N}=F_{W} \sin \theta \\
F_{S N}=F_{S} \cos \theta \\
W_{N}=W \cos \theta
\end{gathered}
$$




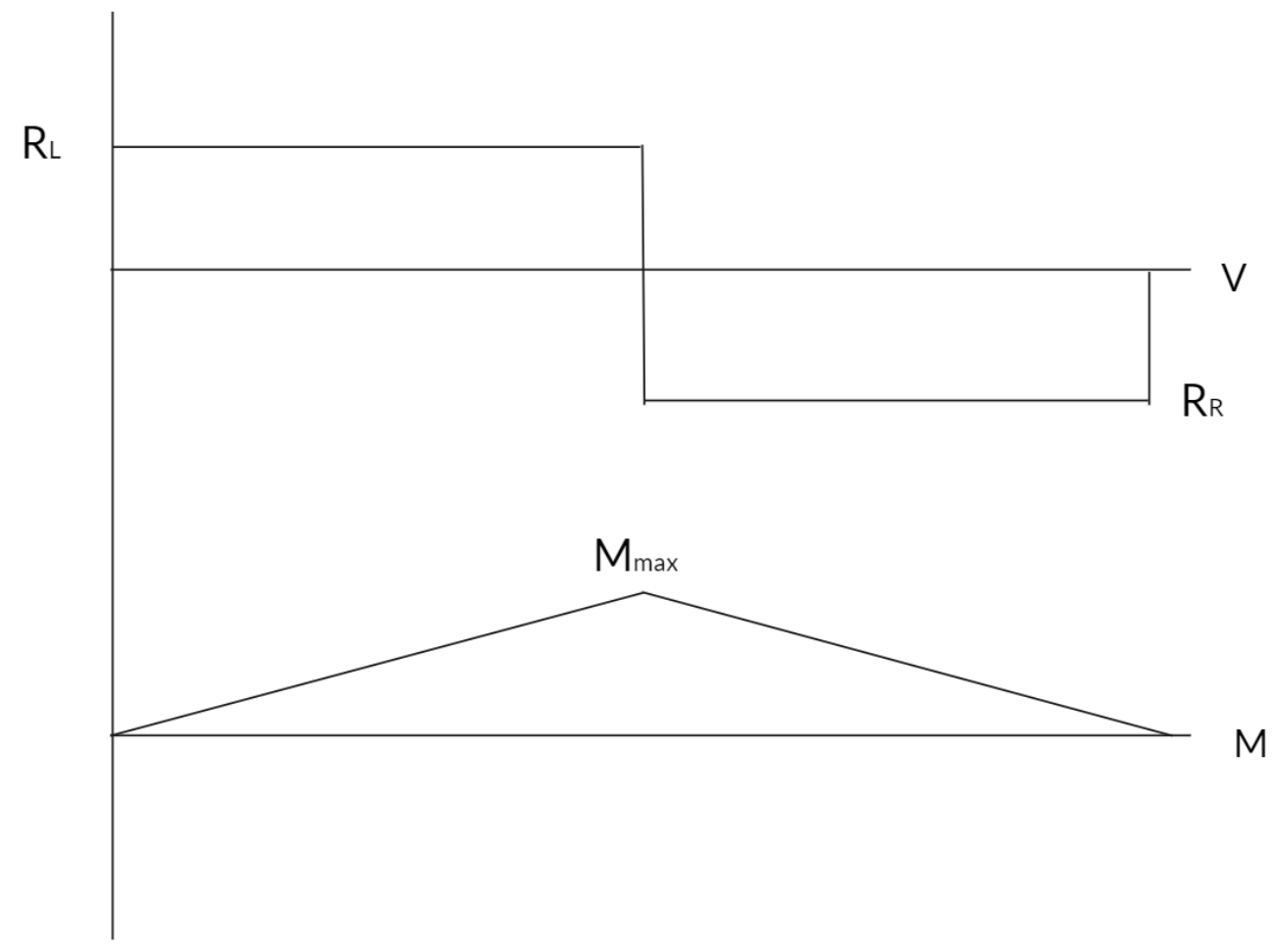

Figure 31 Shear and bending moment diagrams for member AC

The maximum bending moment is at the center of the beam.

$$
\begin{gathered}
R_{L}=R_{R}=\frac{F_{W N}+F_{S N}+W_{N}}{2} \\
M_{\text {max }}=R_{L} \frac{P}{2} \\
\sigma=\frac{M}{S} \\
S=\frac{I}{C}=\frac{1}{6} b h^{2}
\end{gathered}
$$

The cross-sectional dimensions $\mathrm{b}$ and $\mathrm{h}$ can be obtained through calculating $\mathrm{S}$ (elastic section modulus) when the yield stress $\sigma_{Y}$ of the material is known. 
Lastly, to resist wind forces from the left (positive $\mathrm{x}$ direction) and left (negative $\mathrm{x}$ direction), the system may need to be anchored at points A and B.

Anchoring force at $A$ to resist wind forces from left:

$$
\begin{gathered}
\sum M_{B}=0 \\
F_{w}\left(\frac{h}{2}\right)=\left(F_{S}+W\right)\left(\frac{l}{2}\right)+F_{A}(l) \\
F_{A}=\left(\frac{1}{l}\right)\left[F_{w}\left(\frac{h}{2}\right)-\left(F_{S}+W\right)\left(\frac{l}{2}\right)\right]
\end{gathered}
$$

Anchoring Force at $B$ to resist wind forces from right:

$$
\begin{gathered}
\sum M_{A}=0 \\
\left(W+F_{S}\right)\left(\frac{l}{2}\right)=F_{w}\left(\frac{h}{2}\right)+F_{B}(l) \\
F_{B}=\left(\frac{1}{l}\right)\left[\left(W+F_{S}\right)\left(\frac{l}{2}\right)-F_{w}\left(\frac{h}{2}\right)\right]
\end{gathered}
$$

\subsection{Analysis on Simple DIY Structure}

Analysis was performed using equations from section 5.1 on the sample structure from 5.1. Table 1 lists all constants used to obtain values. Note all external forces considered in the calculations are half of the external force values on the entire system. Wind loading of $51 \mathrm{~m} / \mathrm{s}$ (115 MPH) and snow loading of 4.8kPa (100 PSF) are considered, which are typical design snow loads from ASCE 7-05 for the Keweenaw Peninsula, Michigan. The snow load is converted into a point load at the center of the structure by multiplying by the distributed snow load by the area 
of the panel. The tables provide a list of values as a function of tilt angle, from 0 to 85 degrees in 5-degree increments. The weight of the system is the combined weight of the panel and structure. $40 \mathrm{~kg}$ was used for the entire system mass (400 Newtons) and halved since only half of the system is analyzed (average solar panel mass is $20 \mathrm{~kg}$ ). The dimensions of the module use are average and typical dimensions of modules and the cut sheet for the module used is given in Figure 27.

Table 1 Table of Values Used in Calculations

\begin{tabular}{|c|c|c|}
\hline Area_module & 1.6368 & $\mathrm{~m}^{\wedge} 2$ \\
\hline $\mathbf{p}$ & 1.65 & $\mathrm{~m}$ \\
\hline rho & 1.225 & $\mathrm{~kg} / \mathrm{m}^{\wedge} 3$ \\
\hline V^2 & 2500 & $\mathrm{~m} / \mathrm{s}$ \\
\hline F_s & 3936 & Newtons \\
\hline W_sys & 200 & Newtons \\
\hline F_s + W_sys & 4158.5 & Newtons \\
\hline
\end{tabular}


Table 2 Force in member $C B$ as a function of tilt angle

\begin{tabular}{|c|c|c|c|c|c|}
\hline $\begin{array}{c}\text { Tilt } \\
\text { Angle }\end{array}$ & $h(m)$ & $I(\mathrm{~m})$ & Area $\left(m^{\wedge} 2\right)$ & F_w (N) & $F_{-} c b(N)$ \\
\hline 0 & 0.00 & 1.65 & 0.00 & 0.00 & 2068.00 \\
\hline 5 & 0.14 & 1.64 & 0.14 & 113.63 & 2072.97 \\
\hline 10 & 0.29 & 1.62 & 0.28 & 226.40 & 2087.96 \\
\hline 15 & 0.43 & 1.59 & 0.42 & 337.45 & 2113.21 \\
\hline 20 & 0.56 & 1.55 & 0.56 & 445.93 & 2149.15 \\
\hline 25 & 0.70 & 1.50 & 0.69 & 551.01 & 2196.47 \\
\hline 30 & 0.83 & 1.43 & 0.82 & 651.90 & 2256.19 \\
\hline 35 & 0.95 & 1.35 & 0.94 & 747.83 & 2329.82 \\
\hline 40 & 1.06 & 1.26 & 1.05 & 838.07 & 2419.61 \\
\hline 45 & 1.17 & 1.17 & 1.16 & 921.93 & 2528.96 \\
\hline 50 & 1.26 & 1.06 & 1.25 & 998.77 & 2663.14 \\
\hline 55 & 1.35 & 0.95 & 1.34 & 1068.01 & 2830.64 \\
\hline 60 & 1.43 & 0.83 & 1.42 & 1129.13 & 3045.85 \\
\hline 65 & 1.50 & 0.70 & 1.48 & 1181.65 & 3335.03 \\
\hline 70 & 1.55 & 0.56 & 1.54 & 1225.17 & 3751.07 \\
\hline 75 & 1.59 & 0.43 & 1.58 & 1259.38 & 4418.03 \\
\hline 80 & 1.62 & 0.29 & 1.61 & 1284.00 & 5708.95 \\
\hline 85 & 1.64 & 0.14 & 1.63 & 1298.84 & 9490.92 \\
\hline
\end{tabular}

Table 2 provides the compressive forces on member $\mathrm{CB}$ as a function of tilt angle. As tilt angle approaches 90 degrees, the force in $\mathrm{CB}$ grows large due to the maximum $\sin (90)$ component, reaching almost $9.5 \mathrm{kN}$. However, common tilt angles during winter may be closer to 60-70 degree range, for example in the Keweenaw Peninsula, with forces in CB between 3 and $3.75 \mathrm{kN}$. 
Table 3 Bending moment in member AC as a function of tilt angle and normal forces; Maximum moment occurs at center of member $A C$

\begin{tabular}{|c|c|c|c|c|c|c|c|c|c|}
\hline $\begin{array}{c}\text { Tilt } \\
\text { Angle }\end{array}$ & $h(m)$ & $I(\mathrm{~m})$ & $\begin{array}{c}\text { Area } \\
\left(m^{\wedge} 2\right)\end{array}$ & F_w (N) & $\begin{array}{c}\text { F_wn } \\
(\mathrm{N})\end{array}$ & $\begin{array}{l}\text { F_sn } \\
(\mathrm{N})\end{array}$ & $\begin{array}{l}W_{-} n \\
(N)\end{array}$ & $\begin{array}{c}\text { R_I=R_r } \\
\text { (N) }\end{array}$ & $\begin{array}{c}\text { M_max } \\
(\mathbf{N m})\end{array}$ \\
\hline 0 & 0.00 & 1.65 & 0.00 & 0.00 & 0.00 & 3936.00 & 222.50 & 2079.25 & 1715.38 \\
\hline 5 & 0.14 & 1.64 & 0.14 & 113.63 & 9.90 & 3921.02 & 221.65 & 2076.29 & 1712.94 \\
\hline 10 & 0.29 & 1.62 & 0.28 & 226.40 & 39.31 & 3876.20 & 219.12 & 2067.32 & 1705.54 \\
\hline 15 & 0.43 & 1.59 & 0.42 & 337.45 & 87.34 & 3801.88 & 214.92 & 2052.07 & 1692.96 \\
\hline 20 & 0.56 & 1.55 & 0.56 & 445.93 & 152.52 & 3698.63 & 209.08 & 2030.11 & 1674.84 \\
\hline 25 & 0.70 & 1.50 & 0.69 & 551.01 & 232.87 & 3567.23 & 201.65 & 2000.87 & 1650.72 \\
\hline 30 & 0.83 & 1.43 & 0.82 & 651.90 & 325.95 & 3408.68 & 192.69 & 1963.66 & 1620.02 \\
\hline 35 & 0.95 & 1.35 & 0.94 & 747.83 & 428.94 & 3224.18 & 182.26 & 1917.69 & 1582.10 \\
\hline 40 & 1.06 & 1.26 & 1.05 & 838.07 & 538.70 & 3015.15 & 170.44 & 1862.15 & 1536.27 \\
\hline 45 & 1.17 & 1.17 & 1.16 & 921.93 & 651.90 & 2783.17 & 157.33 & 1796.20 & 1481.87 \\
\hline 50 & 1.26 & 1.06 & 1.25 & 998.77 & 765.10 & 2530.01 & 143.02 & 1719.07 & 1418.23 \\
\hline 55 & 1.35 & 0.95 & 1.34 & 1068.01 & 874.87 & 2257.60 & 127.62 & 1630.04 & 1344.78 \\
\hline 60 & 1.43 & 0.83 & 1.42 & 1129.13 & 977.85 & 1968.00 & 111.25 & 1528.55 & 1261.05 \\
\hline 65 & 1.50 & 0.70 & 1.48 & 1181.65 & 1070.94 & 1663.43 & 94.03 & 1414.20 & 1166.71 \\
\hline 70 & 1.55 & 0.56 & 1.54 & 1225.17 & 1151.29 & 1346.19 & 76.10 & 1286.79 & 1061.60 \\
\hline 75 & 1.59 & 0.43 & 1.58 & 1259.38 & 1216.47 & 1018.71 & 57.59 & 1146.38 & 945.77 \\
\hline 80 & 1.62 & 0.29 & 1.61 & 1284.00 & 1264.49 & 683.48 & 38.64 & 993.30 & 819.47 \\
\hline 85 & 1.64 & 0.14 & 1.63 & 1298.84 & 1293.90 & 343.05 & 19.39 & 828.17 & 683.24 \\
\hline
\end{tabular}

The maximum bending moment occurs at the center of member $A C$ at length $P / 2$.

Above the neutral axis, member $A C$ is in compression, and below the neutral axis, member $A C$ is in tension. The maximum moment experienced along $A C$ is when the structure is flat, at 0degree tilt angle. 
Table 4 Required anchoring forces to withstand plan east and plan west direction winds

\begin{tabular}{|c|c|c|c|c|c|c|}
\hline Tilt Angle & $\mathbf{h}(\mathbf{m})$ & $\mathbf{I}(\mathbf{m})$ & Area $\left(\mathbf{m}^{\wedge} \mathbf{2}\right)$ & $\mathbf{F} \mathbf{w}(\mathbf{N})$ & Anchor in A & Anchor in B \\
\hline 0 & 0.00 & 1.65 & 0.00 & 0.00 & -2068.00 & 2068.00 \\
\hline 5 & 0.14 & 1.64 & 0.14 & 227.27 & -2058.06 & 2058.06 \\
\hline 10 & 0.29 & 1.62 & 0.28 & 452.81 & -2028.08 & 2028.08 \\
\hline 15 & 0.43 & 1.59 & 0.42 & 674.90 & -1977.58 & 1977.58 \\
\hline 20 & 0.56 & 1.55 & 0.56 & 891.85 & -1905.70 & 1905.70 \\
\hline 25 & 0.70 & 1.50 & 0.69 & 1102.02 & -1811.06 & 1811.06 \\
\hline 30 & 0.83 & 1.43 & 0.82 & 1303.80 & -1691.62 & 1691.62 \\
\hline 35 & 0.95 & 1.35 & 0.94 & 1495.66 & -1544.36 & 1544.36 \\
\hline 40 & 1.06 & 1.26 & 1.05 & 1676.14 & -1364.78 & 1364.78 \\
\hline 45 & 1.17 & 1.17 & 1.16 & 1843.86 & -1146.07 & 1146.07 \\
\hline 50 & 1.26 & 1.06 & 1.25 & 1997.54 & -877.71 & 877.71 \\
\hline 55 & 1.35 & 0.95 & 1.34 & 2136.03 & -542.72 & 542.72 \\
\hline 60 & 1.43 & 0.83 & 1.42 & 2258.25 & -112.30 & 112.30 \\
\hline 65 & 1.50 & 0.70 & 1.48 & 2363.29 & 466.05 & -466.05 \\
\hline 70 & 1.55 & 0.56 & 1.54 & 2450.35 & 1298.14 & -1298.14 \\
\hline 75 & 1.59 & 0.43 & 1.58 & 2518.75 & 2632.06 & -2632.06 \\
\hline 80 & 1.62 & 0.29 & 1.61 & 2567.99 & 5213.90 & -5213.90 \\
\hline 85 & 1.64 & 0.14 & 1.63 & 2597.68 & 12777.83 & -12777.83 \\
\hline
\end{tabular}

Table 4 provides suggested values for ballast or anchoring forces at points $A$ and $B$ in order to resist wind loads from the positive or negative $\mathrm{x}$ direction, to prevent rotation about $\mathrm{A}$ or B and keep the system secured to the ground. Anchoring in A and B are equal in magnitude and opposite in direction. 


\subsection{PV Racking Manufacturers and Cost}

Table 5 All information gathered from manufacturer website in July 2019

\begin{tabular}{|c|c|c|c|c|c|c|c|}
\hline Manufacturer & $\begin{array}{c}\text { Type of } \\
\text { Mounting }\end{array}$ & \# of Modules & Rails & Material & \begin{tabular}{|c|} 
Mounting \\
Hardware and \\
Support
\end{tabular} & Notes & Cost USD \\
\hline APA Solar Racking & $\begin{array}{l}\text { APA Ground } \\
\text { Screw, TITAN }\end{array}$ & & & & Geoballast & & $0.29 / \mathrm{W}$ \\
\hline DPW Solar & $\begin{array}{c}\text { Side of Pole } \\
\text { Mount }\end{array}$ & 1 panel & & & & & 240 \\
\hline IronRidge & $\begin{array}{l}\text { "Ground Mount } \\
\text { System" }\end{array}$ & $\begin{array}{l}\text { up to } 5 \text { panels } \\
\text { per column }\end{array}$ & $\begin{array}{c}\text { XR1000 Rails } \\
11^{\prime}, 14^{\prime}, 17^{\prime}\end{array}$ & $\begin{array}{l}\text { Anodized } \\
\text { Aluminum }\end{array}$ & $\begin{array}{c}\text { Steel pipes or } \\
\text { mechanical } \\
\text { tubing or } 2 \times 4 \\
\text { presure treated } \\
\text { wood; Caps } \\
(\$ 4.50), \\
\text { connectors } \\
(\$ 16), \text { UFO } \\
(\$ 0.75)\end{array}$ & $\begin{array}{c}10 \mathrm{yr} \text { structural, } \\
20 \mathrm{yr} \\
\text { functionality }\end{array}$ & $\begin{array}{r}\text { 65, 83, } 99 \\
\text { Respectively } \\
11^{\prime}, 14^{\prime}, 17^{\prime} \\
\end{array}$ \\
\hline MT Solar & Pole Mount & 4-32 modules & & & $\begin{array}{c} \\
\mathrm{SCH} 40 \text { or } \mathrm{SCH} \\
80 \text { Pipe Not } \\
\text { Included }\end{array}$ & $\begin{array}{c}\text { MT Solar } \\
\text { 4-TOP-4-60C } \\
\text { TPM Complete } \\
\text { Kit Standard } \\
\text { Frame, For (4) } \\
60 \text {-Cell } \\
\text { Modules, } \\
2 \mathrm{H} \times 2 \text { W-Landsca } \\
\text { pe, 4" } \\
\end{array}$ & $\begin{array}{c}820-6,300 \text { ( } 4-32 \\
\text { modules, } \\
\text { respsectively) } \\
0.82 / \mathrm{W} \text { for four } \\
250 \mathrm{~W} \text { modules, } \\
0.78 / \mathrm{W} \text { for } \\
32-250 \mathrm{~W} \\
\text { modules }\end{array}$ \\
\hline SnapRack & $\begin{array}{l}122^{\prime \prime} \& 162^{\prime \prime} \\
\text { Ground Rail }\end{array}$ & $\begin{array}{l}\text { For } 3 \text { panels up } \\
\text { to } 39.5^{\prime \prime} \text { wide. }\end{array}$ & $\begin{array}{l}122^{\prime \prime} \& 162 " \\
\text { Ground Rail }\end{array}$ & $\begin{array}{c}6063 \text { Aluminum } \\
\text { Anodized }\end{array}$ & & $\begin{array}{c}\text { (122.00 x } 5.00 \mathrm{x} \\
4.00) \text { in } \\
49.54 \mathrm{lbs} \\
\text { Wind Loads: } 170 \\
\text { mph } \\
\text { Snow Loads: } 120 \\
\text { psf } \\
\text { Design Uplift Load: } \\
340 \text { lbs } \\
\text { Torque } \\
\text { Specification: Rail } \\
\text { and module } \\
\text { attachment: Silver } \\
\text { Hardware } 10-16 \\
\text { ft-lbs, Black } \\
\text { Hardware } 8-10 \\
\text { ft-llbs }\end{array}$ & $\begin{array}{l}134 \text { (pair) } \\
.18 / \mathrm{W} \text { for } \\
3-250 \mathrm{~W} \\
\text { modules }\end{array}$ \\
\hline Unirac & $\begin{array}{l}\text { Ground Fixed } \\
\text { Tilt (low profile, } \\
\text { clicksys, U-LA) }\end{array}$ & & $168^{\prime \prime}$ rail & & & & $\begin{array}{c}0.68 / \mathrm{W} \\
0.45 / \mathrm{W}, 1.15 / \mathrm{W} \\
\text { respectively }\end{array}$ \\
\hline Unistrut & Unistrut rail & & $\begin{array}{c}12 \text { gauge } 20^{\prime} \\
\text { strut } 1-5 / 8 x \\
1-5 / 8\end{array}$ & $\begin{array}{c}\text { pre-galvanized } \\
\text { steel }\end{array}$ & & & 68.44 \\
\hline
\end{tabular}




\subsection{PV Installation Quotes}

Table 6 All costs obtained by quotes through installer

\begin{tabular}{|c|c|c|c|c|c|c|}
\hline & & System & Module Size & No. of & Cost & System Cost \\
Installer & Racking Used & Size (kW) & (Watts) & Modules & USD/Watt & USD \\
\hline Sunrise Solar & IronRidge & & & & & \\
\hline Soofing & XR100 Rails & 13 & 325 & 40 & 2.6 & 33800 \\
Optimum & Unirac & 14.5 & 330 & 44 & 3.77 & 54665 \\
\hline Evergreen & Snapnrack & 14.2 & 330 & 43 & 3.5 & 49700 \\
\hline
\end{tabular}

\subsection{DIY System Cost of Materials}

Cost of a $1.375 \mathrm{~kW}, 5$ panel, 275 watts/panel system_USD 0.17 per watt

Table 7 All prices obtained from McMaster-Carr

\begin{tabular}{|c|c|c|c|}
\hline Material & Qty & Price/Unit [USD] & Total Price [USD] \\
\hline 2"x4"x 8" pressure treated wood & $\mathbf{1 4}$ & 5 & 70 \\
\hline 4" x 4" angle bracket (galvanized steel) & $\mathbf{2 0}$ & 5.5 & 110 \\
\hline 1/4" x 1 1/2" lag screw (pack of 100) & $\mathbf{1}$ & 8.7 & 8.7 \\
\hline \#12 x 3" deck screw (pack of 25) & $\mathbf{4}$ & 11.83 & 47.32 \\
\hline
\end{tabular}

Total system cost is USD 236 


\subsection{Material Properties}

The most commonly used and easily accessible materials used in construction in Molinopampa, Peru are: pine, cedar, and lumber from native trees called ishpingo (Amburana cearensis native to South America) and aliso (native to this region of Peru). There have been several reforestation initiatives in the last 10-20 years in Molinopampa and other parts of Peru with pine trees, which the community has been using more frequently in building structures in the last 5-10 years. Native trees such as ishpingo and aliso are found in abundance in the forests of Molinopampa and have been used for centuries. Red cedar is also found in this region and used for furniture. In the case of remote, rural areas, PV racking materials would ideally comprise of as much local materials as possible to reduce costs from transportation and outside sourcing. 
Table 8 Properties obtained from Mechanics of Materials, Beer. F

\begin{tabular}{|c|c|}
\hline Material & Yield Strength [ksi] \\
\hline Aluminum Alloy 7075-T6 & 73 \\
\hline Aluminum Alloy 6061 & 35 \\
\hline Polycarbonate Plastic & 9 \\
\hline Structural Steel (ASTM-A36) & 36 \\
\hline Structural Steel (ASTM-A913 Grade 65) & 65 \\
\hline Timber - Pine & 6 \\
\hline Timber - Cedar & 3.3 \\
\hline
\end{tabular}




\section{Conclusion and Future Work}

The methodology and analysis provided is a guide for users to understand requirements for analyzing a DIY PV racking system. The analysis provided shows resulting forces on members of the structure that can be used to calculate cross sectional dimensions to design a DIY system. Cross sectional dimensions can be found using material properties (yield strength) and maximum axial loads in member BC, and by using bending moment and yield stress of member AC. Stresses can be compared for a variety of materials and dimensions. Suggested dimensions based on loading will be provided in future work.

The cost of the proposed DIY is 0.17 USD. Installation costs range from USD 2.6-3.7; racking costs would need to be extracted from this price to compare to the proposed DIY rack cost. Structural analysis can also be performed on existing racking systems to compare to various DIY systems. It can be seen from the load analysis that off-the-market racks are overdesigned even for regions such as the Upper Peninsula that experience snow loading of $4.8 \mathrm{kN}$ and wind loads of $51 \mathrm{~m} / \mathrm{s}$. In environments where there is no snow load and little wind loading, maximum compressive forces would be much less than those provided in this analysis. Thus, proprietary rails that boast large load resistances are inappropriate for many applications and further development of PV racking is necessary to lower their costs. This paper serves as a preliminary guide for users to understand considerations for designing a DIY PV system and make PV racking knowledge more accessible. If racking prices do not reduce, PV technology will not easily reach rural communities without external initiatives. The cost of overestimation and 
conservative designs is passed on to the user -in many cases who are large corporations and megawatt farms that can afford these costs. Exploration of sustainable PV racking can be combined with 3D printing and recycled plastic printing can be useful for increasing access to PV technology especially in rural communities. 


\section{References}

A. Kopp, Gregory \& Farquhar, Steve \& J. Morrison, Murray. (2012). Aerodynamic mechanisms for wind loads on tilted, roof-mounted, solar arrays. Journal of Wind Engineering and Industrial Aerodynamics. 111. 40-52. 10.1016/j.jweia.2012.08.004.

Abiola-Ogedengbe, Ayodeji, Hangan, Horia, and Siddiqui, Kamran. "Experimental Investigation of Wind Effects on a Standalone Photovoltaic (PV) Module." Renewable Energy 78 (2015): 657665. Web.

Acker, Richard H, and Kammen, Daniel M. "The Quiet (energy) Revolution: Analysing the Dissemination of Photovoltaic Power Systems in Kenya." Energy Policy 24.1 (1996): 81-111. Web.

Aly, Aly Mousaad, and Bitsuamlak, Girma. "Aerodynamics of Ground-Mounted Solar Panels: Test Model Scale Effects." Journal of Wind Engineering \& Industrial Aerodynamics 123.PA (2013): 250-260. Web.

ASCE. 2010. Minimum Design Loads for Buildings and Other Structures. ASCE/SEI Standard 710.

Beer, Ferdinand P. Mechanics of Materials. New York: McGraw-Hill Higher Education, 2009

Browne, M., Gamble, S., and Gibbons, M. "Wind Turbulence and Load Sharing Effects on Ballasted Roof-Top Solar Arrays." N.p., 2013. 448-459. Print. 
Daisuke Somekawa, Tetsuro Taniguchi, Yoshihito Taniike. Wind Loads Acting on PV Panels and Support structures With Various Layouts. The Eighth Asia-Pacific Conference on Wind Engineering, December 10-14, 2013, Chennai, India http://www.iawe.org/Proceedings/8APCWE/Daisuke\%20Somekawa.pdf

David Ockwell, and Rob Byrne. Sustainable Energy for All: Innovation, Technology and ProPoor Green Transformations. Taylor and Francis, 2016. Web.

Wolfgang Sachs. The Development Dictionary : a Guide to Knowledge as Power. London ; Atlantic Highlands, N.J. :Zed Books, 1992.

Feldman, David et al. "Photovoltaic System Pricing Trends: Historical, Recent, and Near-Term Projections 2015 Edition:" (2015): n. pag. Web.

Fu, Ran; Feldman, David; Margolis, Robert; Woodhouse, Mike; Ardani, Kristen. "U.S. Solar Photovoltaic System Cost Benchmark: Q1 2017." National Renewable Energy Laboratory (NREL), Golden, CO (United States), 2017. Print.

Holmes, John et al. "Smart Villages." Science 350.6259 (2015): 359-359. Web. https://www.iea.org/sdg/

Matasci, Sara. "Solar Panel Cost: Avg. Solar Panel Prices by State in 2019: EnergySage." Solar News, EnergySage, 5 June 2019, news.energysage.com/how-much-does-the-average-solarpanel-installation-cost-in-the-u-s/. 
Mehrdad Shademan, Horia Hangan, Wind Loading on Solar Panels at Different Inclination Angles, 2009 http://www.iawe.org/Proceedings/11ACWE/11ACWE-Shademan.pdf

Ockwell, David et al. "The Uptake and Diffusion of Solar Power in Africa: Socio-Cultural and Political Insights on a Rapidly Emerging Socio-Technical Transition." Energy Research \& Social Science 44 (2018): 122-129. Web.

Pearce, J.M. "Photovoltaics - A Path to Sustainable Futures." Futures 34.7 (2002): 663-674. Web.

Pearce, Joshua, Meldrum, Jay, and Osborne, Nolan. "Design of Post-Consumer Modification of Standard Solar Modules to Form Large-Area Building-Integrated Photovoltaic Roof Slates." Designs 1.2 (2017): n. pag. Web.

Plante, Russell H. Solar Energy, Photovoltaics, and Domestic Hot Water : a Technical and Economic Guide for Project Planners, Builders, and Property Owners . First edition. San Diego, California ;: Academic Press, 2014. Print.

Reina, Giovanni Paolo, and De Stefano, Giuliano. "Computational Evaluation of Wind Loads on Sun-Tracking Ground-Mounted Photovoltaic Panel Arrays." Journal of Wind Engineering \& Industrial Aerodynamics 170 (2017): 283-293. Web.

Rolffs, Paula, Ockwell, David, and Byrne, Rob. "Beyond Technology and Finance: Pay-as-YouGo Sustainable Energy Access and Theories of Social Change." Environment and Planning A 47.12 (2015): 2609-2627. Web. 
Schiffer, Michael Brian. "The Impact of Electricity: Development, Desires and Dilemmas by Tanja Winther." American Anthropologist Dec. 2009: 546-547. Web.

SEAOC. "Structural Seismic Requirements and Commentary for Rooftop Solar PV Arrays."

SEAOC, www.seaoc.org/store/ViewProduct.. spx?id=9173838.

Stathopoulos, Ted, Zisis, loannis, and Xypnitou, Eleni. "Local and Overall Wind Pressure and Force Coefficients for Solar Panels." Journal of Wind Engineering \& Industrial Aerodynamics 125.C (2014): 195-206. Web.

Truman, Harry, S. Inaugural Address. 20 Jan. 1949, Washington D.C.

Ulsrud, Kirsten et al. "Pathways to Electricity for All: What Makes Village-Scale Solar Power Successful?" Energy Research \& Social Science 44 (2018): 32-40. Web.

Ulsrud, Kirsten et al. "The Solar Transitions Research on Solar Mini-Grids in India: Learning from Local Cases of Innovative Socio-Technical Systems." Energy for Sustainable Development 15.3 (2011): 293-303. Web.

Vezzoli, Carlo. et al. Designing Sustainable Energy for All Sustainable Product-Service System Design Applied to Distributed Renewable Energy . Cham: Springer International Publishing, 2018. Web.

Warsidio, Workamaw P. et al. "Influence of Spacing Parameters on the Wind Loading of Solar Array." Journal of Fluids and Structures 48 (2014): 295-315. Web. 
Wills, Rosalie. et al. Best Practices for Commercial Roof-Mounted Photovoltaic System Installation. New York, NY: Springer New York, 2015. Web.

Wittbrodt, B.T., and Pearce, J.M. "Total U.S. Cost Evaluation of Low-Weight Tension-Based Photovoltaic Flat-Roof Mounted Racking." Solar Energy 117.C (2015): 89-98. Web.

Wittbrodt, Ben et al. "Distributed Manufacturing with 3-D Printing: a Case Study of Recreational Vehicle Solar Photovoltaic Mounting Systems." Journal of Frugal Innovation 1.1 (2015): 1-7. Web.

Wittbrodt, Ben, and Pearce, Joshua M. "3-D Printing Solar Photovoltaic Racking in Developing World." Energy for Sustainable Development 36 (2017): 1-5. Web. 